\title{
Historia
}

\section{Cambios producidos en el trabajo institucional del cuidado masculino y femenino en tres hospitales del Antiguo Régimen Castellano al tránsito a la Contemporaneidad}

Changes produced in the institutional work of the masculine and feminine care in three hospitals of the Old Regime to Contemporary Age Mudanças acontecidas no trabalho institucional do cuidado masculino e feminino em três hospitais do Antigo Regime Castellano para o trânsito da contemporaneidade

Paula Ermila Rivasplata Varillas

Doctora en Europa, mundo mediterráneo y su difusión Atlántica. Universidad Pablo Olavide de Sevilla. Cómo citar este artículo en edición digital: Rivasplata Varillas, P.E. (2015). Cambios producidos en el trabajo institucional del cuidado masculino y femenino en tres hospitales del Antiguo Régimen Castellano al tránsito a la Contemporaneidad. Cultura de los Cuidados (Edición digital), 19, 42. Disponible en: http://dx.doi.org/10.14198/cuid.2015.42.07>

Correspondencia: Calle Bilbao 119. Urbanización San Bernardo. Distrito Pueblo Libre. Lima-Perú Dirección postal: Lima-21

Correo electrónico: Correo electrónico: rivasplatavarillas@gmail.com. Recibido: 10/01//2015; Aceptado: 08/06/2015

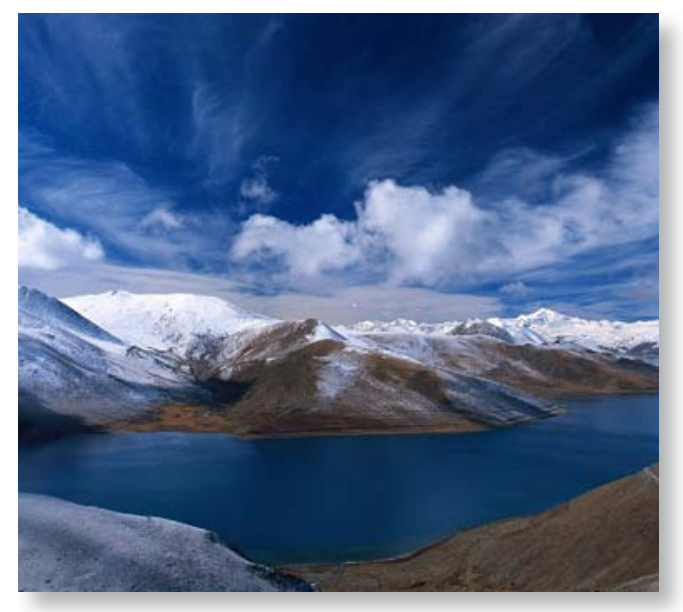

\section{ABSTRACT}

This article aims to compare the changes in the institutional work of male and female care in three hospitals in the Castilian area during the Old Regime to the transit to Contemporary Age. Case studies are the hospital of San Hermenegildo and the hospital of the Five Wounds, both located in Sevilla capital. These hospitals will be compared with the hospital of Saint Bartholomew of Lima in the Viceroyalty of Perú. In the transition of the modernity to the contemporary Age, the political and institutional support that received the development and study of the medicine in the Spanish monarchy, transformed the care into the hospitals that produced, even, the supplanting of the ancient nurse feminine work, exercised in the women's hospitals, for medical instructors in medicine.

Key words: Woman, Gender, Old Regime, Contemporary Age, hospitals, job. 


\section{RESUMO}

Este artigo tem como objetivo comparar as mudanças no trabalho institucional do cuidado masculino e feminino em três hospitais no domínio castelhano no período do Antigo Regime à contemporaneidade. Os estudos são o hospital de San Hermenegildo e o hospital das Cinco Feridas, ambos localizados em Sevilha. Esses hospitais são comparados com o hospital de San Bartolomé de la Ciudad de los Reyes no Vice-Reino do Peru. Na transição da modernidade para o contemporaneidad, o apoio político e institucional que recebeu o desenvolvimento e estudo da medicina na monarquia espanhola trouxe mudanças na gestão do cuidado de hospital para o ponto do a suplantación da trabalho feminino, exercitado nos hospitais de mulheres pelos médicos em medicina.

Palavras-chave: Mulher, Gênero, Antiguo Régime, contemporaneidade, hospitais, trabalho.

\section{RESUMEN}

Este artículo tiene el propósito de comparar los cambios producidos en el trabajo institucional del cuidado masculino y femenino en tres hospitales en el ámbito castellano en el periodo del Antiguo Régimen al tránsito a la contemporaneidad. Los casos de estudio son el hospital de San Hermenegildo y el hospital de las Cinco Llagas, ambos ubicados en Sevilla. Estos hospitales se compararan con el hospital de San Bartolomé de la Ciudad de los Reyes en el Virreinato del Perú. En la transición de la modernidad a la contemporaneidad, el apoyo político e institucional que recibió el desarrollo y estudio de la medicina en la monarquía española produjo cambios en la gestión del cuidado hospitalario al punto de la suplantación del trabajo asistencial femeni- no, ejercido en los hospitales de mujeres, por practicantes en medicina.

Palabras clave: Mujer, Género, Antiguo Régimen, Contemporaneidad, hospitales, trabajo.

\section{INTRODUCCIÓN}

Los cambios que alteraron estructuralmente a los hospitales se gestaron desde mediados del siglo XVIII con la reforma universitaria de 1771 durante el reinado de Carlos III que impulsó el estudio de la medicina en las universidades y la creación de nuevas escuelas de cirugía. Estos cambios produjeron un aumento de estudiantes y egresados en medicina y cirugía que estuvieron unidas a las reformas hospitalarias. También impactaron los conflictos bélicos e la inflación galopante que provocaron cambios estructurales y alteraron el desenvolvimiento de los hospitales estudiados, sobre todo del trabajo femenino.

Pero para poder entender cómo estos y otros cambios estructurales afectaron a los tres hospitales estudiados, es necesario conocer la evolución de ellos. El Hospital de San Hermenegildo o del Cardenal de Sevilla, fundada en 1453, estaba dirigido fundamentalmente para heridos y enfermos de sexo masculino que eran atendidos por un equipo encabezado por un médico y un cirujano, un enfermero mayor y cuatro menores. Todo varón era considerado capaz y habilitado para el cargo de enfermero mayor si había asistido a las curaciones de los enfermos y practicado en el hospital al menos por tres años, bajo la dirección y enseñanza de médicos y cirujanos. En más, todos los enfermeros estaban obligados a asistir a las clases de anatomía y cirugía que se daban en el hospital, si querían conservar el trabajo. Evidentemente, no existían enfermeras, pero tuvo un área 
femenina conectada con el hospital a través de un torno, tras la cual se recluían mujeres que se encargaban de la cocina y el lavado de la ropa, bajo la dirección de una madre mayor.

En cuanto al Hospital de las Cinco Llagas o de la Sangre de Sevilla, fundado en 1500, se produjeron los cambios en el trabajo institucional del cuidado de manera paulatina e, incluso, se resistió y fue forzado a asumirlos. La razón estaría en su naturaleza femenina, es decir, era un hospital de mujeres atendidas casi exclusivamente por viudas y solteras. Sin embargo, a pesar de haber sido durante algún tiempo un hospital mixto no existe información documental de enfermeros a excepción de los dirigidos a eclesiásticos de forma esporádica (ADPS. Legajo 1B. Autos capitulares de 1556 a 1584, f.27v). Los cambios se aceleraron a partir de la ocupación francesa de la ciudad de Sevilla, las sucesivas desamortizaciones eclesiásticas y terminaron en 1837 cuando se convirtió en Hospital Central (Giménez, 2006). Sin embargo, la centralización no tuvo efecto hasta el año 1844, en que se dotó al hospital del personal necesario, del reglamento y del sistema de contabilidad.

Si comparamos el Hospital del Cardenal con el Hospital de mujeres de la Sangre, en ésta última no existió academia alguna de medicina, aunque se pretendió crear una a mediados del siglo XVIII, sin éxito alguno (Domínguez Rodino, 1989). De esto se podría derivar que el desarrollo de la ciencia médica fue eminentemente androcéntrico, habiendo sido vedado en establecimientos de carácter femenino el desarrollo de la ciencia por el tabú que despertaban los cuerpos femeninos, una de las causantes de la supina ignorancia frente a sus enfermedades. Así y todo en el Hospital de las Cinco Llagas previa licencia de los padres priores a veces se realizaban disecciones cadavéricas de algunas pacientes al ignorar la causa de sus muertes, realizado por el médico, cirujano y con la presencia de un tercer jurisconsulto.

Estos dos hospitales sevillanos eran eclesiásticos y compartían dos patronos, los priores de los monasterios de San Jerónimo de Buenavista y Santa María de las Cuevas y estaban bajo la protección del Papa, a quien tenían que solicitar permiso para cualquier cambio o modificación. Además, ambos hospitales estaban regidos por frailes y administrados por clérigos -administrador, secretario notario, mayordomo y curas- y tenían un área de clausura femenina con mujeres que trabajaban bajo las ordenes de una madre mayor.

El otro caso analizado se localizaría en las Indias, en el virreinato del Perú, una extensión del reino castellano, durante el siglo XVII a comienzos del XIX. Se trata del Hospital San Bartolomé de la ciudad de Lima donde se recibían a enfermos de ambos sexos, por lo que existían enfermeros y enfermeras. En este hospital se observa más claramente los cambios producidos en el trabajo institucional del cuidado masculino $\mathrm{y}$ femenino de un hospital en el lapso de 1667 a 1817. Así, los enfermeros y enfermeras cumplían labores asistenciales en el siglo XVII, que las enfermeras mantenían a comienzos del siglo XIX. Sin embargo, los enfermeros llevaban ese título a fuerza de la costumbre, pues se trataban, en realidad, de médicos y alumnos practicantes del Colegio de Medicina y Cirugía de San Fernando

\section{OBJETIVO E HIPOTESIS}

El objetivo de este trabajo es conocer y comparar los cambios producidos en el trabajo institucional del cuidado masculino y femenino en tres hospitales castellanos, de los cuales 
dos eran sevillanos y uno indiano. Se tratan de los hospitales de San Hermenegildo y el de las Cinco Llagas de Sevilla y el hospital de San Bartolomé de Lima en el Virreinato del Perú. Tres casos de estudio diferentes: un hospital de hombres, otro de mujeres y el último mixto y colonial.

La hipótesis sugerida sería que los cambios políticos, culturales, económicos y sociales que se produjeron en la monarquía española desde fines del XVIII a comienzos del XIX, como el apoyo político e institucional que recibió el desarrollo y estudio de la medicina en la monarquía española, produjeron cambios en la gestión del cuidado hospitalario al punto de la suplantación del trabajo asistencial femenino, ejercido en los hospitales de mujeres, por practicantes en medicina.

La comparación de los tres hospitales castellanos se hizo con el propósito de demostrar que se produjo un proceso de cambio en el trabajo institucional del cuidado masculino y femenino en los hospitales castellanos que fue casi simultánea en España y en la Indias, en este caso en Sevilla y en Lima.

En el caso peruano, el proceso de reorganización hospitalaria se dio antes de la independencia de España, producto de las reformas universitarias y hospitalarias intrínsecas tardo coloniales que se aceleraron con los acontecimientos políticos, económicos y culturales (Rivasplata, 2015). Mientras que en Sevilla fue un proceso político paulatino de desamortización de los bienes eclesiásticos que se desencadenó abruptamente con la implantación de la política liberal en 1836 y la expulsión de los religiosos de la gestión hospitalaria.

\section{MÉTODO Y FUENTES}

Este trabajo se realizó recurriendo a la hermenéutica y heurística. Las líneas de análisis que se utilizaran para llegar a identificar los cambios en el trabajo institucional del cuidado masculino y femenino en los hospitales castellanos fueron:

1. Las características generales de cada hospital estudiado

2. Los cambios experimentados por los cuidadores masculinos y femeninos de cada hospital.

3. Comparaciones entre los tres hospitales.

Las fuentes primarias utilizadas provienen del archivo de la Diputación Provincial de Sevilla (ADPS) donde se ha consultado los diversos libros y legajos del hospital de las Cinco Llagas y del hospital de San Hermenegildo. Específicamente, las constituciones, los libros de juntas patronales, libros de recibo y gasto, libros de salarios, inventarios, testamentos, libro de cuentas, entre otros. Además, se ha recurrido para consultas puntuales a los protocolos de notarios públicos de Sevilla, que se encuentran en el Archivo Histórico Provincial de Sevilla (AHPS). En cuanto al estudio del hospital de San Bartolomé de la ciudad de Lima en el Virreinato del Perú se ha consultado las fuentes documentales que se encuentran en el Archivo General de Indias (AGI) y el Archivo de la Beneficencia de Lima (ABL).

\section{DESARROLLO DEL TEMA}

1.-El Hospital de San Hermenegildo de Sevilla, también llamado del Cardenal.

El Hospital del Cardenal de Sevilla fue fundado por Don Juan de Cervantes, cardenal de la Iglesia de Roma y arzobispo de Sevilla, el año de 1453, obteniéndose bula del Papa Nicolás V para su erección. Este hospital tuvo por objetivo la curación de hombres heridos, por "bocas de fuego", espadas, puñales que provocaban dislocaciones, quebraduras de brazos piernas $y$ 
huesos. También atendían mordeduras de perros y otros animales venenosos, quemaduras y otra cualquier herida que no habían pasado a ser llagas que necesitasen de "mercuriales" para su curación.

El gobierno del hospital fue asumido por un priorato compuesto por tres patronos perpetuos, que eran el cabildo de la Iglesia Metropolitana y Patriarcal de Sevilla, el cual señalaba cada dos años un diputado capitular canónigo que asistía en nombre y representación del cabildo y por los padres priores de los monasterios de Santa María de las Cuevas de la Cartuja y de San Jerónimo de Buenavista. Estos priores realizaban todos los años, dos visitas generales y varias juntas particulares para controlar la entrada de caudales por el mayordomo, lo gastado para el sustento por el administrador y el modo como se trataba a los enfermos por los cuidadores.

Este priorato recurrió a un sacerdote para administrar, gobernar y regir en lo espiritual y temporal al hospital, sus enfermerías, ministros, hacienda, dando cuenta al priorato de todo lo que ocurría en el hospital. Los patronos nombraban a un secretario contador, un eclesiástico secular, que cuidaba el archivo y sus papeles y a un mayordomo eclesiástico para la cobranza de las fincas y rentas del hospital. Había dos curas para la atención espiritual de los enfermos.

El hospital tenía cincuenta camas y aún más, según el número de enfermos que concurriesen al hospital, siendo esta su característica principal, es decir, no tener un número limitado de camas, atendiendo sin excepción a cuantos viniesen a cualquier hora del día o de la noche. En este hospital se curaba las heridas, estando para este fin en dichas enfermerías un cirujano mayor, un enfermero mayor, cuatro enfermeros y un boticario. El acceso a uno de

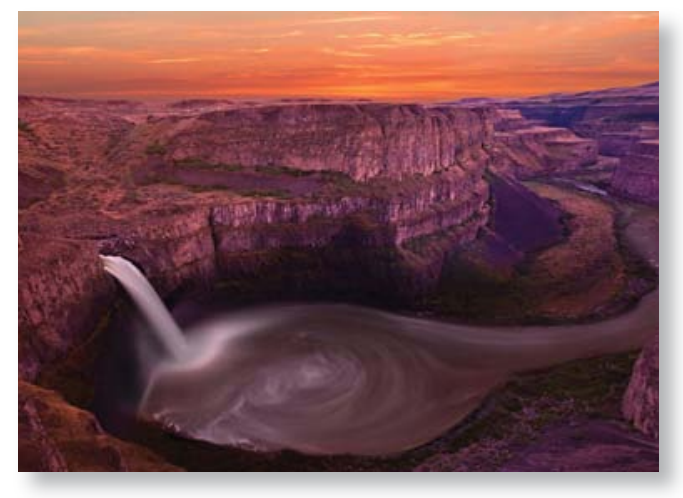

estos cargos era a través de un examen de conocimientos entre las personas que asistían a las curaciones de los enfermos, llamados practicantes. De esta manera, existió en el hospital del Cardenal una academia de anatomía donde se daba las nociones prácticas de asistencia a los heridos, debido a lo cual este hospital tenía prestigio en cuanto a realizar acertadas curaciones. Además, no sólo se encargaban de recibir a los heridos en el hospital, dándoles cama, sino que el enfermero mayor tenía por obligación salir al portal del hospital diariamente a curar cuantos hombres y mujeres acudieran con heridas frescas. Este hospital tenía dos enfermerías una baja para el tiempo de verano y otra alta para el invierno. En cada ambiente había una habitación cerrada y separada para los enfermos más graves que habían perdido el sentido por las erisipelas $u$ otras fiebres que les sobrevenían a las heridas, para los que drenaban "copiosas materias que su fetor molesta" $y$ para los que debido a sus heridas penetrantes tornaban débiles "tísicos o éticos". La separación de los enfermos más graves se realizaba con el fin de lograr mayor comodidad, alivio y descanso de los otros enfermos. Las camas eran de tablas y bancos de fierro, unas para el verano y otras para el invierno con colchones de lana, almohadas, sábanas y cobertores y para el verano colchas de "calimanco" y a cada enfermo se le daba un saco de paño color par- 
do para que se pusiese cuando se sentaba en la cama o se levantaba. Se podían mudar de ropa cuantas veces se considerase necesario ya que este hospital iban heridos.

Los eclesiásticos y sirvientes vivían en el hospital, pero no los médicos ni los cirujanos. Los sacerdotes realizaban misas al mártir San Hermenegildo y misas de difuntos a las diversas capellanías que albergaba. El cuidado de la iglesia estaba a cargo de un sacristán. El hospital tenía un portero para recibir a los heridos a cualquier hora de la noche y llevarlos a curar a la enfermería. Y asimismo había un botiller que era el que tenía todas las provisiones. Este oficio por lo regular se le daba a un enfermero de los más diestros que había cumplido algunos años en la enfermería. También estaba el despensero y el barrendero que era el que barría los patios, partía la leña y hacía algunos mandados. Las rentas de este hospital provenían de los inquilinos de las numerosas casas arrendadas y de las rentas de tierras, dotaciones, tributos y juros.

\subsection{La preparación del enfermero en el Hos- pital del Cardenal}

En el Hospital del Cardenal había un médico, un cirujano, un enfermero mayor y cuatro mozos, el primero de estos últimos se denominaba "medicinero" que cumplía con dar las medicinas que mandaban los galenos antes de comer. El enfermero mayor no podía estar más de cinco años en el hospital desde 1685, siendo ratificado en 1746. La razón de que permanecieran en el cargo tan poco tiempo era para que diseminaran por el mundo los conocimientos quirúrgicos adquiridos en el hospital durante el proceso enseñanza aprendizaje.

Los jóvenes que trabajaban atendiendo a los heridos en este hospital, recibían bajos salarios y se les exigía obediencia, disciplina y respeto a la institución, obligándolos a no salir del hospital más que un día a la semana. Sólo algunos podían acceder a una plaza de enfermero en el hospital, previo examen, y no por eso ganaban más.

Hasta mediados del siglo XVII, el personal médico no titulado seguía estando formado por un enfermero mayor y cuatro enfermeros. Sin embargo, desde 1745, el hospital obligó al enfermero mayor que fuese cirujano para ocupar la plaza. Con anterioridad a esta fecha no era necesario ese título para adjudicarse la plaza. Incluso para ingresar al hospital y acceder al peldaño más inferior del sistema del cuidado, practicante de enfermería asalariado, se tuvo que concursar.

El personal titulado, es decir, los médicos y cirujanos del Hospital del Cardenal pertenecieron a los círculos más prestigiosos de Sevilla, llegando a formar parte de la Regia Sociedad de Filosofía y Medicina de Sevilla desde 1700, organizándose actos de aprendizaje como las lecciones de anatomía en los hospitales del Amor de Dios, Espíritu Santo y el San Hermenegildo. Así, en 1743, los patronos del hospital ordenaron que "la Academia que siempre ha habido en este hospital en la que se controvierte y enseña la Cirugía, se tenga en la enfermería presidiéndola el enfermero mayor del dicho hospital o el Cirujano mayor si estuviere presente" (ADPS. Legajo 3. El Hospital del Cardenal). Alusión evidente a la enseñanza de cirugía que, al menos, desde el siglo XVII, se venía realizando en el hospital.

De esta manera en el Hospital del Cardenal funcionaba una academia de enseñanza de anatomía, cirugía y técnicas de sangrado donde se preparaban los aprendices de enfermería en los quehaceres de su profesión. Existía un aula de aprendizaje para tal fin que estaba a cargo del cirujano y enfermero mayor. Esta 
academia atrajo al hospital a jóvenes que venían a aprender y estaban obligados a asistir a las charlas y prácticas, así como, los enfermeros menores o practicantes del hospital, pues el que no concurría se le despedía del empleo ya que su obligación era prepararse para examinarse.

Se adjudicaba el cargo de enfermero previo examen realizado ante el médico y el cirujano. Por ejemplo, a finales del siglo XVIII se presentó una plaza vacante de "practicante de enfermería” en el Hospital del Cardenal, el cirujano mayor y el enfermero mayor avisaron a los sujetos que concurrían a la academia y a las horas de curación de los pacientes, para que se presentaran como pretendientes si querían ser examinados para el nombramiento de la plaza, ya que el nombramiento se obtenía previo examen.

El examen se realizaba en presencia del administrador quien tomaba la decisión final una vez que el cirujano y enfermero mayor le notificaban el candidato más idóneo para el cargo (ADPS. Legajo 2. Hospital El Cardenal). De esta manera, en 1792, se presentaron Antonio Fernández, Fernando Vizcarra y Manuel Rodríguez a un puesto de practicante de enfermero. Se les interrogó por separado sobre osteología, miología y angiología, es decir, tratados sobre huesos, músculos y venas. El primer examinado Antonio Fernández tenía tres años de academia y había acumulado experiencia por su asistencia en las curaciones llevadas a cabo en la enfermería, además, sabía sangrar perfectamente. En cuanto a los dos restantes tenían tres a cuatro meses de asistencia en la academia y en la curación que ofrecía el Hospital San Hermenegildo. El poco tiempo acumulado sólo les había permitido tener principios de anatomía. Por lo tanto, el cirujano mayor del Hospital del Cardenal Fulgencio Xímenez de Cisneros y el practicante mayor Dn. Francisco Antonio Promeno ante el administrador del hospital Sr. Dn. Manuel Antonio del Paz eligieron para la plaza vacante de practicante de enfermero a Antonio Fernández.

De esta manera, el Hospital del Cardenal tenía enfermeros que en realidad eran practicantes en cirugía:

"Deseando los señores patronos que en la enfermería de este hospital haya practicantes hábiles y capaces de sostener el honor que este hospital siempre ha tenido por los buenos cirujanos que de él han salido. Acordaron que cuando haya vacantes de practicantes se haya de hacer examen por el cirujano mayor y enfermero mayor del hospital ante el Sr. administrador o el que le suceda en su ausencia a los que concurran a la academia de cirugía que diariamente hay en este hospital y preside el enfermero mayor para que hecha la consulta por los dos referidos cirujanos ante el referido administrador de la mejor suficiencia de los examinados proponga esta al señor patrono presidente el más idóneo o los que estuvieren en igual grado para que dicho señor patrono nombre la plaza que estuviere vacante" (ADPS. Legajo 2. Hospital El Cardenal).

El 31 de marzo de 1792, el prior de San Jerónimo de Buena Vista Fr. Seferino de Zafra manda al administrador del Hospital del Cardenal Juan Manuel de Paz que nombre al nuevo enfermero practicante:

"que acordado en la junta general atento a la provisión de las plazas de practicantes que se examinasen los pretendientes o opositores por el cirujano mayor y enfermero y estos diesen una graduación y certificación jurada de la idoneidad y cumplimiento del examen de los dichos opositores y en su vista proveer el patrono con- 
forme es justo para lo cual mandará Vuestra merced que formen las dichas examinadores la graduación de los tres opositores con especificación de los méritos y habilidad y remiéndamela proveeré” (ADPS. Legajo 2. Hospital El Cardenal).

En el Hospital del Cardenal también se realizaron exámenes de cirugía para aspirantes al título. Su elección venía determinada por la propia naturaleza del centro asistencial, cuyo objetivo era atender a heridos que facilitaba abundante material humano de traba- jo, característica que le había proporcionado tradición y prestigio en la Sevilla del Antiguo Régimen. De esta manera, en 1789, Juan Sixto Rodríguez, primer examinador de cirugía por la Subdelegación del Real Protomedicato de Sevilla, solicitó a la dirección del hospital una sala para examinar otorgándosele la "sala que llaman de los Esqueletos y están en las enfermerías altas del hospital". Esta sala era una habitación con bastante iluminación natural donde había láminas de anatomía, un esqueleto e instrumentos de cirugía. Esta aula tenía el siguiente material didáctico:

\begin{tabular}{|l|l|}
\hline \multicolumn{2}{|l|}{ Tabla 1. Relación de láminas de la academia de anatomía del Hospital del Cardenal de } \\
Sevilla
\end{tabular}




\begin{tabular}{|l|l|}
\hline Lamina 20 & Mitad de la pelvis vista de lado y el fémur en toda su extensión. \\
\hline Lamina 21 & Vasos del cutis. \\
\hline Lamina 22 & $\begin{array}{l}\text { Los troncos de las arterias, carótidas y cervicales como asimismo las venas } \\
\text { yugulares. }\end{array}$ \\
\hline Lamina 23 & Los vasos de la dura mater. \\
\hline Lamina 24 & $\begin{array}{l}\text { Corte vertical de la cabeza y cuello divididos en partes simétricas, de la parte } \\
\text { anterior a la posterior. }\end{array}$ \\
\hline Lamina 25 & $\begin{array}{l}\text { Un corte horizontal la cabeza abierta en ángulo derecho y también por medio } \\
\text { de distintos cortes practicados en la cara: la parte anterior del cerebro, los } \\
\text { conductos lacrimales, el seno maxilar derecho abierto. }\end{array}$ \\
\hline Lamina 26 & Un corte vertical de la cabeza y una sección vertical de los huesos del cráneo. \\
\hline Lamina 27 & La superficie de la lengua también la parte lateral interna de las narices. \\
\hline Lamina 28 & Un corte horizontal de las narices y el cerebro y su base. \\
\hline Lamina 29 & Las partes de la generación del hombre. \\
\hline Lamina30y31 & Las partes internas y externas de la generación de la mujer. \\
\hline Lamina 32 & El corazón con sus vasos. \\
\hline Lamina 33 & Los pulmones son sus vasos por la parte posterior. \\
\hline Lamina 34 & El hígado visto por su parte y también los intestinos y el estómago. \\
\hline \multicolumn{1}{|c|}{ Fuente: ADPS. Legajo 2. Hospital del Cardenal o San Hermenegildo de Sevilla. } \\
\hline
\end{tabular}

\subsection{El área de mujeres del Hospital del Car- denal}

Este hospital estaba orientado al cuidado de hombres y mujeres que habían sufrido heridas violentas. Sólo los hombres podían ocupar camas, las mujeres se les curaban en el portal del hospital, es decir fuera de él, por lo tanto, la atención y cuidado estaba a cargo de un enfermero mayor y cuatro enfermeros menores. En el área femenina del hospital, las mujeres se dedicaban a las labores de cocina, lavado, amasado y cocido del pan, estaban a cargo de la madre mayor y estaban obligadas a vivir en reclusión. El "cuarto de mujeres" era bastante pequeño, ocupando la zona denominada la "Torre" que estaba en casa aparte, en la zona más retirada y separada de este hospital.

Desde su creación en 1453, había tres madres, cada una de las cuales tenía dos doncellas, a las cuales se les daba 1.000 maravedíes como ayuda a su buen estado de vida y 20.000 mrs como dote, después de haber trabajado por tres años consecutivos en el hospital (Cabré I Pairet, 2006). En 1588, habían dos ma- dres, la madre de la Torre (ropera) y la madre del pan (panadera) a quienes desde ese año se les aumentó a dos ducados mensuales su salario y 25.000 maravedíes por las raciones de comida anuales y ayudas de costa de 100 reales, ganando el doble de las madres y doncellas del Hospital de la Sangre (un ducado mensual). Sin embargo, se redujo el número de madres, quedando sólo la madre mayor o "de la Torre" quien dirigía a siete mozas en el XVII y ocho en el XVIII. También había una portera que nunca llegó a ser "madre" que siempre estaba en el torno para el despacho de lo que se ofreciese hasta 1822. Durante estos siglos, en el cuarto de mujeres se realizaba el lavado de la ropa y el guisado de la comida y lo entregaban a través del torno, no teniendo comunicación alguna con los demás ministros y sirvientes del hospital. Estas mujeres no aseaban ni limpiaban las enfermerías, pues de eso se encargaban los enfermeros menores. Aunque dos veces al año cuando se producía el cambio de las estaciones, se hacía una limpieza general de las enfermerías altas o bajas según correspondiese, 
encargándose a mujeres externas del hospital por lo cual recibían una paga.

En el XIX, la madre mayor ya no aparece en los libros salarios desde antes 1804, siendo reducidas las doncellas, ya llamadas sirvientes, a sólo tres bajo la dirección de una mujer, la madre mayor jubilada Marina Cantero quien al fallecer la sucedió Ángela Velos, desde 1815 a 1822 (ADPS. Libro 12. Hospital del Cardenal. Libros de salarios de ministros). Esta mujer al jubilarse constituyó la última en gozar los privilegios que ofrecía este hospital. Desde 1815, el secretario del hospital empezó a omitir los nombres de las mujeres que trabajaban en el área femenina quienes se pierden en el anonimato, recibiendo la responsable del área femenina, Ángela Velos, la paga a nombre de las mujeres que trabajaban en el hospital, sin embargo los nombres de los estudiantes practicantes figuran en los libros.

\subsection{Salarios del personal hospitalario del Cardenal}

Desde el siglo XVI, el personal hospitalario que obtenía mayores ganancias en el Hospital del Cardenal eran los eclesiásticos -el administrador, el secretario, el cura principal- y los sanitarios titulados, sobre todo, el cirujano. Todos los demás trabajadores recibían salarios bajísimos. En el siglo XVIII, los salarios se mantuvieron fijos a excepción del administrador y cirujano que tendían a la alza. El cirujano ganaba 37.400 maravedíes mucho más que el médico 10.000 mrs y el enfermero 10.200 mrs y esto se explica porque este hospital fue creado para curar heridos provocados por accidentes violentos. A medida que se acercaba el final del siglo XVIII, desde 1770 a 1802, el salario del cirujano se incrementó drásticamente de $98.192 \mathrm{mrs}$ a $124.100 \mathrm{mrs}$ frente a 22.400 mrs del médico y $20.200 \mathrm{mrs}$ del enfermero quien había asumido la labor de sangrador además de enfermero para obtener el salario indicado, incrementando obligaciones para ganar más dinero. Los salarios de los ministros de menor rango entre los que estaban los cuatro enfermeros menores se estancaron en todo el siglo XVIII, recibiendo el primer enfermero llamado "medicinero" $8.789 \mathrm{mrs}$ y los restantes $4.896 \mathrm{mrs}$.

A esto se unía que todos recibían una ración de comida diaria, por ejemplo, en 1782, el enfermero tenía derecho a dos libras de pan y doce cuartos para carne, un cuartillo de aceite, los sábados dos huevos, los viernes pescados y en vigilias diez libras de tocino anuales. Se les entregaba un cuartillo y medio de vino durante los siglos XVI y XVII.

"Los cuatro enfermeros menores y al boticario se le den cada día un cuartillo y medio de ración de vino, no se les dé en dinero y de la misma manera se les dé ración de cuartillo $y$ medio de vino al portero y lacayo y que a la madre del pan y de la cocina se les dé un cuartillo de vino a cada una de ellas cada un día atento a que son mujeres mayores" (ADPS. Libro 1 A. Libro del Hospital del Cardenal 1574-1616, f. 22 r, 04/10/1583).

El salario del personal femenino se mantuvo tal cual a lo largo del siglo XVIII. La responsable de esta área, la madre mayor era la que recibía el mayor salario 8.976 mrs que desde 1742 se le adosó la ayuda de costa anual de 200 reales, alcanzando un salario de 15.776 mrs., la madre tornera y las doncellas desde su creación y durante todo el siglo XVIII ganaron siempre lo mismo $4.488 \mathrm{~ms}$. Se debe tener en cuenta que los trabajadores de algunos hospitales cobraban en dinero y en especie, de modo que los niveles salarias en metálico bajísimos eran compensados con raciones diarias de comida (Rey Castelao, 2010), como era el caso de los hospitales estudiados. 
En el siglo XIX es cuando se produjo un giro drástico en los salarios y se uniformizaron e igualaron los salarios de las mujeres y desapareció la jerarquía establecida bajo una madre mayor (Carbonell Esteller, 1989). Cada una de estas mujeres recibió el más bajo salario del hospital.

Desde 1804, al enfermero mayor se le empieza a denominar cirujano segundo, pues ya se le consideraba como tal al exigírsele el título, como consecuencia, se produce un aumento vertiginoso en su salario en siete y medio veces más sobre su valor, siguiendo de cerca al cirujano primero como sería llamado al cirujano mayor. Los enfermeros menores son denominados practicantes de cirugía, como estudiantes que eran se les aumentó levemente sus salarios. Mientras tanto un porterobarrendero siguió ganando más que cualquier practicante de cirugía.

Al final se puede indicar que el acceso al conocimiento científico permitió al enfermero mayor ser reconocido como cirujano por lo que desde 1804, en el hospital ya consideraba que tenía dos cirujanos y cuatro practicantes de cirugía.

\begin{tabular}{|c|c|c|c|c|c|}
\hline & 1701 & 1713 & 1742 & $\begin{array}{l}1776- \\
1802 \\
\end{array}$ & 1804 \\
\hline Administrador & 38.436 & 38.436 & 70.000 & 70.000 & 374.000 \\
\hline Secretario & 37.400 & 37.400 & 37.400 & 55.808 & 272.000 \\
\hline Cura primero & 19.204 & 17.572 & 17.572 & 17.512 & 221.000 \\
\hline Cura segundo & 15.057 & 15.057 & 15.940 & 15.940 & 204.000 \\
\hline Sacristán & 5.712 & 5.712 & 5.712 & 5.712 & 93.500 \\
\hline Médico & 10.000 & 10.000 & 18.700 & 22.440 & 27.064 \\
\hline Cirujano mayor & 37.400 & 37.400 & 40.800 & 124.100 & 149.600 \\
\hline Enfermero mayor & 10.200 & 10.200 & 10.200 & 20.200 & 112.200 \\
\hline Barbero sangrador & 10.000 & 10.000 & 10.000 & & \\
\hline Boticario & 13.464 & 13.464 & 13.464 & 13.464 & 102.000 \\
\hline Enfermero primero & 7.344 & 7.344 & 7.344 & 7.344 & 74.800 \\
\hline Enfermero segundo & 4.896 & 4.896 & 4.896 & 4.896 & 61.200 \\
\hline Enfermero tercero & 4.896 & 4.896 & 4.896 & 4.896 & 61.200 \\
\hline Enfermero cuarto & 4.896 & 4.896 & 4.896 & 4.896 & 61.200 \\
\hline Botiller & 7.106 & 7.106 & 7.106 & 7.106 & \\
\hline Portero & 6.000 & 6.000 & 6.000 & 6.000 & 74.800 \\
\hline Barrendero & 6.732 & 6.732 & 4.173 & 4.173 & \\
\hline Despensero & 13.464 & 13.464 & 13.464 & 13.464 & 74.800 \\
\hline Dos Pajes del administrador & 11.424 & 11.424 & 11.424 & 11.424 & \\
\hline Cochero & 8.976 & 8.976 & 8.976 & 8.976 & \\
\hline Criado del mayordomo & 8.160 & 8.160 & 8.160 & 8.160 & \\
\hline Madre Mayor & 8.976 & 8.976 & 15.776 & 8.976 & \\
\hline Tornera & 4.488 & 4.488 & 4.488 & 4.488 & \\
\hline Cada uno de las 8 doncellas & 4.488 & 4.488 & 4.488 & 4.488 & 51.000 \\
\hline Abogado & 3.000 & 3.000 & 3.000 & 3.000 & \\
\hline Procurador & 3.000 & 3.000 & 3.000 & 3.000 & \\
\hline Paje del secretario & 8.976 & 8.976 & 8.976 & 8.976 & \\
\hline Maestro herrador & 5.610 & 5.610 & 5.610 & 5.610 & \\
\hline
\end{tabular}




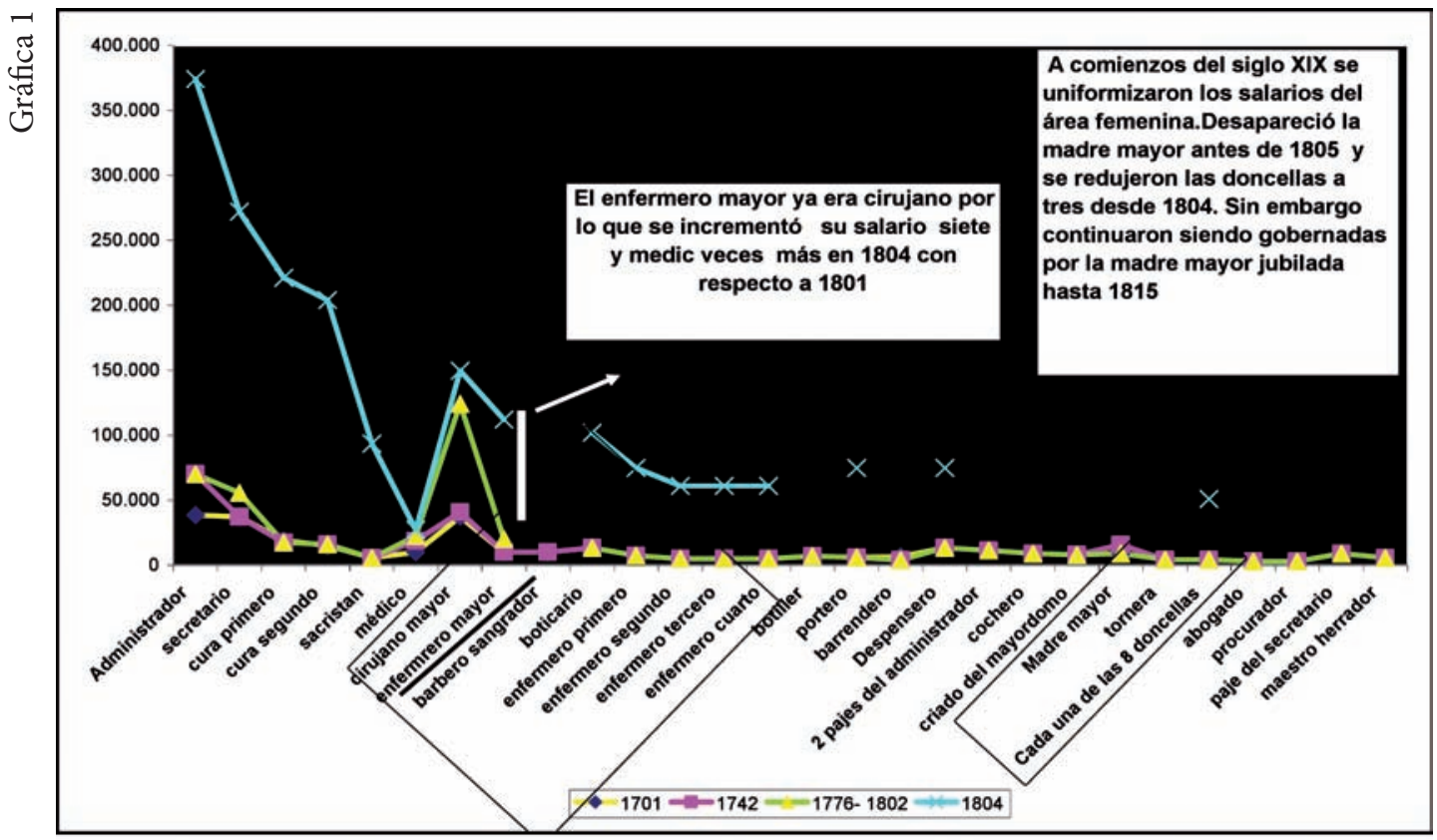

Fuente

ADPS. Hospital San Hermenegildo. Legajos 2,108, 109,110, 111 y 112. Elaboración propia

Salario de los ministros y criados del hospital del Cardenal de Sevilla(maravedies) del año de 1713

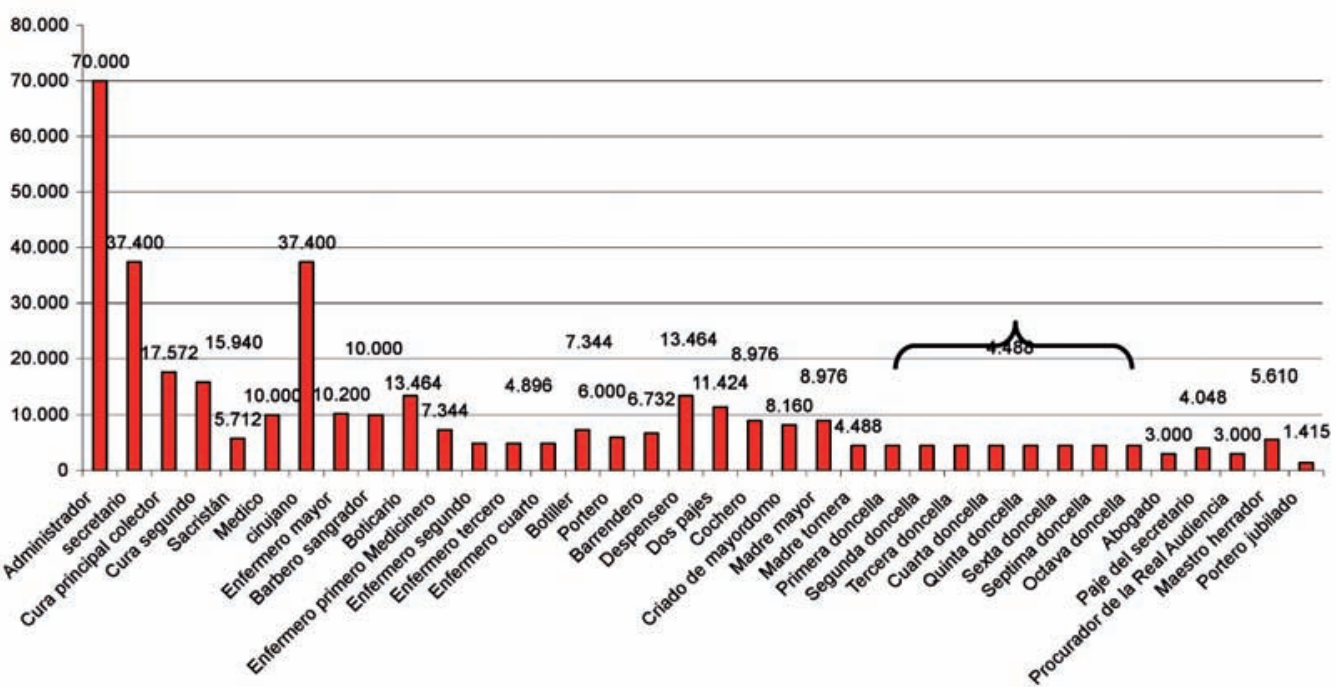

Fuente: ADPS. Hospital del Cardenal de Sevilla. Legajo 2. "Sumario de lo pagado de salarios a los ministros de este hospital este año de 1713. Asi atrasados como corrientes cuya razón y recibos se hallaran en el libro de salarios", f. 98 r. 


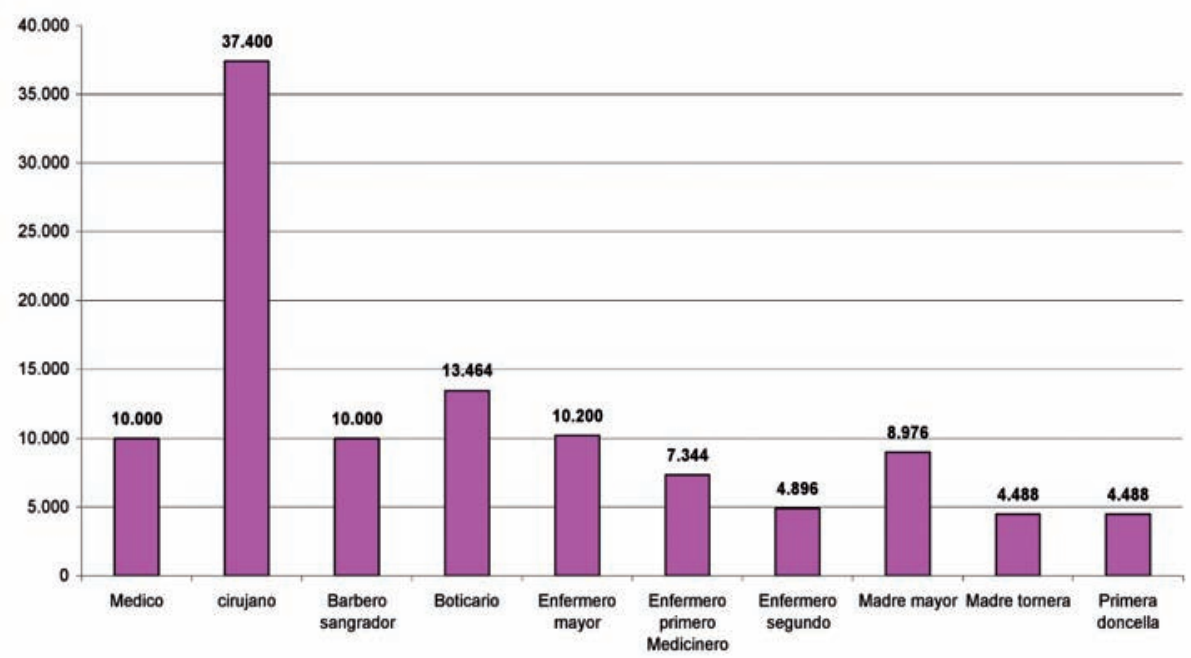

Fuente: ADPS. Hospital del Cardenal de Sevilla. Legajo 2. "Sumario de lo pagado de salarios a los ministros de este hospital este año de 1713. Asi atrasados como corrientes cuya razón y recibos se hallaran en el libro de salarios", f. 98 r.

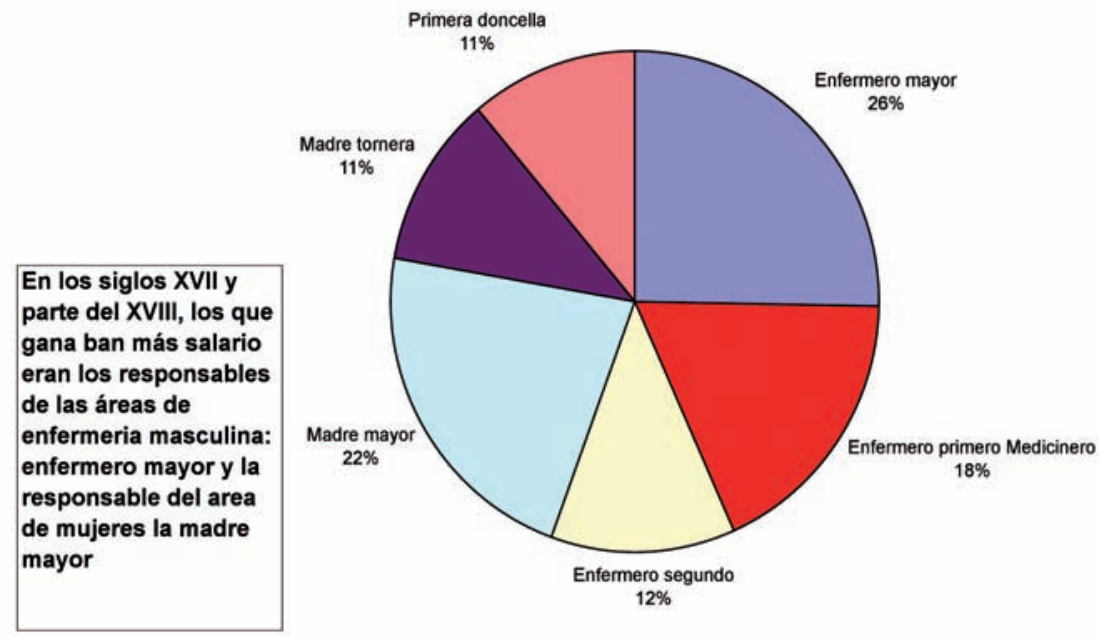

Fuente: ADPS. Hospital del Cardenal de Sevilla. Legajo 2, f. 98 r. 


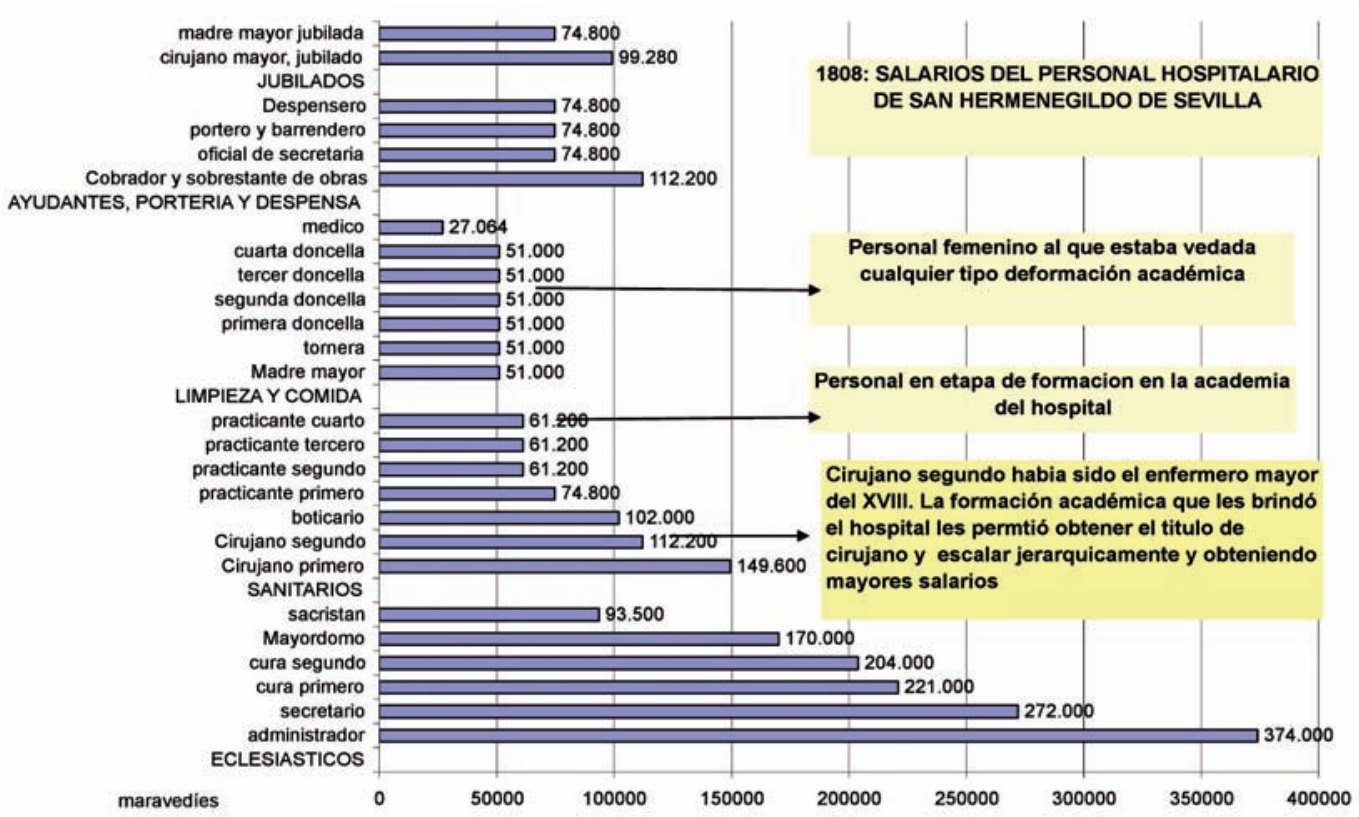

De esta manera, en cuanto al personal sanitario del hospital obtenía mayor salario el cirujano, seguido del boticario, enfermero mayor, sangrador, médico y madre mayor. Al comparar sus salarios, se puede sacar como conclusión que el enfermero mayor podía ganar un poco más que la madre mayor del Hospital del Cardenal si hacía de sangrador. Después de estos ministros mayores seguían los practicantes de enfermería y las doncellas. La profesión de cirujano desbancó definitivamente a la del médico en el Hospital del Cardenal donde ganaba más, pero no hay que olvidar que era un hospital especializado en heridos, sin embargo, ganaban igual que los cirujanos del Hospital de las Cinco Llagas. Los enfermeros menores fueron considerados el último escalafón del personal médico no titulado, aunque ya en proceso de serlo, pues en el XIX fueron denominados practicantes en cirugía. Su número habitual fue de cuatro. En 1713, el enfermero menor "medicinero" recibía 216 reales $y$ el resto de enfermeros menores 144 reales anuales, 12 reales menos que una doncella de dote, quienes permanecieron con sus mismos salarios desde 1603. Los ministros mayores -los eclesiásticos y los cirujanos y médicos titulados- obtenían los más altos ingresos, los demás eran considerados ministros menores y sirvientes.

Paulatinamente, los cambios en el trabajo institucional de este hospital se fueron evidenciando en los salarios a medida que la educación se fue haciendo popular entre los varones (caso del enfermero mayor, reconocido como cirujano segundo en el XIX), permaneciendo vedada a las mujeres.

\section{El hospital de la Sangre de Sevilla}

Este hospital fue fundado en 1500 y estuvo destinado principalmente a la curación de mujeres que no tuviesen enfermedades contagiosas o incurables. Su personal asistencial estaba conformado por un médico, un cirujano, la madre mayor, las nueve madres auxiliares y doce enfermeras menores, llamadas doncellas 
de dote. En este hospital, la mujer cumplió deberes fundamentales para su buen funcionamiento que comprendieron cuidado de enfermas, heridas, convalecientes y desahuciadas, la administración del área femenina y la realización del trabajo doméstico (cocina, limpieza y lavado de ropa). Este hospital estaba regido por un triunvirato de frailes del monasterio de la Cartuja de Santa María de las Cuevas, del monasterio de San Isidoro del Campo y por el monasterio de San Jerónimo de Buenavista. Un clérigo administraba el hospital y había un mayordomo, un contador, un archivero-notario, dos curas, un médico, un cirujano, una madre mayor, madres auxiliares, doncellas de dote y criados. En este hospital prevalecía el concepto de vivir en comunidad, aunque con áreas femeninas y masculinas separadas, pero permeables en ciertos momentos del día para cumplir con el trabajo cotidiano.

\subsection{Salarios de los trabajadores del Hospital de las Cinco Llagas de Sevilla en el siglo XVIII}

Esta parte del trabajo se ha realizado, utilizando los ingresos variables de cada trabajador del Hospital de las Cinco Llagas de Sevilla según los libros de contabilidad de los años de 1710 a 1765 . Se ha utilizado el precio promedio del trigo en Sevilla de los años 1710 a 1765 según la información proporcionada por Pierre Pon-

\begin{tabular}{|c|c|c|c|c|c|c|c|c|c|c|}
\hline \multicolumn{11}{|c|}{ 1710.1765 Ingresos Nominales Hospital de las Cinco Llagas Datos en maravedies } \\
\hline & Precio del Trigo/mrs & Cartuia & San jeronimo & San isidro del Campd & Secretario conts & Cura primero & Cura segundo & Medico & Cirujano & sangrador \\
\hline 1710 & 1484 & 26.112 & 13.974 & 19.074 & 36.550 & 13.617 & & 61.727 & & \\
\hline 1711 & 799 & 33.830 & 19.754 & 25296 & 36.252 & 16.396 & 111.277 & 70.737 & 62.815 & 100.555 \\
\hline 1712 & 875 & 7.956 & 25.857 & 17.544 & 47.056 & 3.400 & & 26.146 & 414.086 & 6.817 \\
\hline 1713 & 841 & 23.256 & 17.544 & 31.144 & 65.770 & 37.586 & 33.624 & 63.316 & 29.602 & 69.239 \\
\hline 1714 & 909 & 2.550 & 20.400 & 31.144 & 92204 & 5.615 & 29.384 & 60.945 & 11.683 & 46.937 \\
\hline 1715 & 799 & 40.029 & 26.214 & 37.262 & 85.935 & 34.119 & 69.507 & 75.973 & & 22.857 \\
\hline 1716 & 739 & 34.578 & 35.190 & 37.172 & 70.611 & 39.936 & 11.606 & 80.716 & & 19.771 \\
\hline 1717 & 589 & 24.854 & 17.204 & 19.380 & 34.773 & 21.887 & 90.055 & 73.372 & & 15.096 \\
\hline 1718 & 603 & 157.456 & 17.204 & 24.642 & 27.508 & 32.949 & 23.705 & 81.600 & & 29.376 \\
\hline 1719 & 739 & 17.204 & 26.180 & 20.604 & 41.472 & 28.486 & 19.740 & 68.000 & & 33.933 \\
\hline 1720 & 450 & 17.204 & 17.204 & 26.180 & 76.080 & 77.004 & 36.869 & 74.800 & & 21.402 \\
\hline 1721 & 510 & 26.180 & 17.204 & 14.382 & 77.302 & 21.471 & & 96.296 & & 36.746 \\
\hline 1722 & 510 & 17.204 & 26.180 & 20.026 & 56.253 & 13.691 & 18.110 & 82.688 & & 22.479 \\
\hline 1723 & 906 & 17.204 & 18.632 & 26.180 & 53.506 & 24.548 & 22.478 & 62.900 & 34.272 & 38.080 \\
\hline 1724 & 974 & 20.162 & 12818 & 12852 & 16.694 & 71.765 & 32.598 & 81.231 & 41.480 & 1.268 \\
\hline 1725 & 875 & 15.674 & 21.162 & 15.674 & 35.964 & 32.935 & 17.000 & 132.872 & 36.924 & 16.796 \\
\hline 1726 & 566 & 24.752 & 24.752 & 29.240 & 27.936 & 8.754 & 8.754 & 74.800 & 36.924 & \\
\hline 1727 & 453 & 26.180 & 17.204 & 17.204 & 30.180 & 8.229 & 8.161 & 74.800 & 37.400 & \\
\hline 1728 & 544 & 14.348 & 23.324 & 11.526 & & 8.500 & 8.554 & 67.082 & 32.963 & \\
\hline 1729 & 637 & 20.060 & 20.060 & 31.858 & 55.872 & 10.273 & 8.334 & 82.518 & 41.837 & \\
\hline 1730 & 586 & 26.180 & 17.204 & 17.204 & & 7.729 & 13.169 & 74.800 & 37.400 & \\
\hline 1731 & 1.037 & 17.204 & 26.180 & 17.204 & 55.872 & 22.704 & 9.104 & 74.800 & 37.400 & \\
\hline 1732 & 892 & 17.204 & 17.204 & 26.180 & 27.936 & 22.479 & 8.879 & 74.800 & 37.400 & \\
\hline 1733 & 799 & 26.180 & 17.204 & 17.204 & 27.936 & 22.129 & 8.529 & 74.800 & 37.400 & \\
\hline 1734 & 1.008 & 17.204 & 26.180 & 17.204 & 27.936 & 19.128 & 13.635 & 74.800 & 37.400 & \\
\hline 1735 & 1.269 & 17.204 & 17.204 & 26.180 & & 25.379 & 11.779 & 74.800 & 37.400 & \\
\hline 1736 & 739 & 26.180 & 17.204 & 17.204 & & 27.304 & 11.154 & 74.800 & 37.400 & \\
\hline 1737 & 1.045 & 17.204 & 26.180 & 17.204 & 91.203 & 23.874 & 10.834 & 97.838 & 37.400 & \\
\hline 1738 & 1.139 & 17.204 & 17.204 & 26.180 & 38.169 & 53.143 & 24.566 & 76.512 & 37.400 & 3.740 \\
\hline
\end{tabular}

Fuente:

ADPS. Legajo 187. Libro de pago de salarios a ministros del Hospital de la Sangre. Salarios de 1708 a 1725. ADPS. Legajo 188.Libro de pago de salarios a ministros del Hospital de la Sangre. Salarios de 1725-1765.ADPS. Legajo 4B. Autos capitulares del hospital de la Sangre de 1716 a 1734. ADPS. Legajo 4B. Libro de autos capitulares pertenecientes al gobierno de este hospital de la Sangre, comienza año de 1734 y acaba con junta de gobierno de 6 de diciembre de 1763 . 
sot en el libro "Atlas de historia económica de la baja Andalucía: siglos XVI-XIX”. Para obtener los salarios reales se eligió el índice precio del trigo de 1711, correspondiendo el año base, con la cual se determinó los ingresos deflactados de los trabajadores del mencionado hospital.
La constitución del hospital estipula salarios fijos, pero en los libros salarios se comprueba que se entregan salarios variables en función de lo que hayan trabajado, comprado en las almonedas del hospital y ahorrado en raciones de comida.

CALCULO DE LOS INGRESOS REALES. DEFLACTAMOS A PARTIR DE 1711
1710-1765 Ingresos Nominales Hospital de las Cinco Llagas Datos en maravedies
Año base $1711=100$

\begin{tabular}{|c|c|c|c|c|c|c|c|c|c|c|}
\hline \\
\hline & & & & & & & & & & \\
\hline & \multicolumn{3}{|c|}{ Precio del Trigon(n) IN inDICE Precil Cartuja } & San jeronimo & San isidro del $\mathrm{Ca}$ & Secretario contad & Cura primero & Cura segundo & Medico & Cirjajno \\
\hline 1710 & 1484 & 185,73 & 14.059 & 7.524 & 10.270 & 19.679 & 7.332 & 0 & 33.234 & 0 \\
\hline 1711 & 799 & 100.00 & 33.830 & 19.754 & 25.296 & 36.252 & 16.396 & 111.277 & 70.737 & 62.815 \\
\hline 1712 & 875 & 109.51 & 7.265 & 23.611 & 16.020 & 42.969 & 3.105 & 0 & 23.875 & 378.120 \\
\hline 1713 & 841 & 105.26 & 22.095 & 16.668 & 29.589 & 62.485 & 35.709 & 31.945 & 60.154 & 28.124 \\
\hline 1714 & 909 & 113,77 & 2.241 & 17.931 & 27.375 & 81.046 & 4.936 & 25.828 & 53.570 & 10.269 \\
\hline 1715 & 799 & 100,00 & 40.029 & 26.214 & 37.262 & 85.935 & 34.119 & 69.507 & 75.973 & 0 \\
\hline 1716 & 739 & 92,49 & 37.385 & 38.047 & 40.190 & 76.344 & 43.178 & 12.548 & 87.269 & 0 \\
\hline 1717 & 589 & 73,72 & 33.715 & 23.338 & 26.290 & 47.171 & 29.691 & 122.163 & 99.532 & 0 \\
\hline 1718 & 603 & 75,47 & 208.636 & 22.796 & 32.652 & 36.449 & 43.659 & 31.410 & 108.123 & 0 \\
\hline 1719 & 739 & 92,49 & 18.601 & 28.306 & 22.277 & 44.839 & 30.799 & 21.343 & 73.521 & 0 \\
\hline 1720 & 450 & 56.32 & 30.547 & 30.547 & 46.484 & 135.084 & 136.725 & 65.463 & 132.812 & 0 \\
\hline 1721 & 510 & 63.83 & 41.015 & 26.953 & 22.532 & 121.106 & 33.638 & 0 & 150.864 & 0 \\
\hline 1722 & 510 & 63.83 & 26.953 & 41.015 & 31.374 & 88.130 & 21.449 & 28.372 & 129.545 & 0 \\
\hline 1723 & 906 & 113,39 & 15.172 & 16.432 & 23.088 & 47.187 & 21.649 & 19.823 & 55.471 & 30.224 \\
\hline 1724 & 974 & 121,90 & 16.539 & 10.515 & 10.543 & 13.695 & 58.871 & 26.741 & 66.636 & 34.027 \\
\hline 1725 & 875 & 109.51 & 14.313 & 19.324 & 14.313 & 32.840 & 30.074 & 15.523 & 121.331 & 33.717 \\
\hline 1726 & 566 & 70,84 & 34.941 & 34.941 & 41.277 & 39.436 & 12.358 & 12.358 & 105.592 & 52.124 \\
\hline 1727 & 453 & 56,70 & 46.176 & 30.344 & 30.344 & 53.231 & 14.514 & 14.394 & 131.932 & 65.966 \\
\hline 1728 & 544 & 68.09 & 21.074 & 34.257 & 16.929 & 0 & 12.484 & 12.564 & 98.527 & 48.414 \\
\hline 1729 & 637 & 79,72 & 25.162 & 25.162 & 39.960 & 70.081 & 12.886 & 10.453 & 103.504 & 52.477 \\
\hline 1730 & 586 & 73,34 & 35.696 & 23.457 & 23.457 & 0 & 10.538 & 17.956 & 101.988 & 50.994 \\
\hline 1731 & 1.037 & 129,79 & 13.256 & 20.171 & 13.256 & 43.049 & 17.493 & 7.015 & 57.633 & 28.816 \\
\hline 1732 & 892 & 111,64 & 15.410 & 15.410 & 23.450 & 25.023 & 20.135 & 7.953 & 67.001 & 33.501 \\
\hline
\end{tabular}

Fuente: El deflactor utilizado es el precio promedio del trigo en Sevilla de los años 1710 a 1765 , según Pierre Ponsot "Atlas de historia económica de la baja Andalucía: siglos XVI-XIX".

El análisis de algunos oficios en el hospital indican que:

a) No hay diferencia sustancial en el trabajo no cualificado tanto de hombres como mujeres desde mediados del siglo XVIII, tendencia que ya se visualiza desde el primer tercio del siglo XVIII.

\section{Explicación:}

Primero se procede a comparar oficios no cualificados aparentemente semejantes.

- Jardinero y cualquier doncella enfermera

- Portero, madre portera y madre tornillera
- Despensero y madre ropera

- Tahonero y madre panetera

Fig. 1. Jardinero y cualquier doncella enfermera

En este primer caso, ambos tienen un mismo estatus dentro del hospital son criados. Se observa que el jardinero tiene menor capacidad adquisitiva que la doncella, pero a mediados del primer tercio el siglo XVIII se invierte la figura, teniendo mayor capacidad adquisitiva el jardinero. Pero es una leve diferencia. 
Fig. 2. Portero, madre portera y madre tornillera

En el segundo caso, los tres son porteros. El portero controla la puerta de entrada. La madre portera controla la entrada al área femenina y la madre tornillera controla el torno, pero principalmente cocina para los varios servidores que trabajaban en esta área. Se observa que el portero tenía una mayor capacidad adquisitiva que la portera y la tornillera, pero en el primer tercio del siglo XVIII, se invierte la figura, teniendo mayor capacidad adquisitiva la portera y la tornillera. Pero es una leve diferencia.

\section{Fig. 3. Despensero y madre ropera}

En el tercer caso, ambos controlan bienes en el almacén y en la ropería. Se observa que el despensero tenía una mayor capacidad adquisitiva que la madre ropera, pero en el primer tercio del siglo XVIII, se invierte la figura, teniendo mayor capacidad adquisitiva la madre ropera. Pero es una leve diferencia.

\section{Fig. 4. Tahonero y madre panetera}

En el cuarto caso, ambos se relacionan con la elaboración del pan del hospital. El tahonero se ocupa de moler los cereales y la madre panetera de la elaboración del pan (preparar, amasar y hornear). Se observa que la capacidad adquisitiva de ambos oficios es semejante. Por lo tanto, desde mediados del siglo XVIII, se deduce que los oficios de baja cualificación ya no se discriminan por género, ni siquiera levemente.

b) En la primera mitad del siglo XVIII, los trabajos cualificados de tipo administrativo y de tipo religioso descienden paulatinamente su capacidad adquisitiva, que alcanzó el tope a mediados del siglo XVII, acercándose a la capacidad adquisitiva de los salarios prove- nientes de los trabajos cualificados femeninos. Explicación:

Primero se procede a comparar oficios cualificados aparentemente semejantes. En el Antiguo Régimen, es muy difícil comparar profesiones semejantes, pero se trata de superar este inconveniente, agrupando profesiones aparentemente análogas. En algunos casos, se agrupan oficios cualificados en mayores y menores, para detectarlos, nos dan una orientación los salarios fijos estipulados por constitución.

- Madre agonizante y cura segundo

- Madre cirujana y el botiller

- Madre mayor y patrón (San Isidoro del Campo)

\section{Fig. 5. Madre agonizante y cura segundo}

En este caso, ambos se ocupan del buen morir. La madre agonizante se ocupaba de la enferma, una vez que el cura semanero le daba la extremaunción. Le rezaba y confortaba para que se enfrente a la muerte en forma serena y no la dejaba sola en ningún momento. La madre agonizante tenía que saber leer para ocupar el cargo, por lo que era un oficio cualificado. El cura segundo se encargaba de ayudar al cura semanero en las misas y entierro. Se observa que a comienzos del siglo XVIII, el cura segundo, oficio cualificado masculino, tiene mayor capacidad adquisitiva que la madre agonizante, pero lo pierde rápidamente a mitad de dicho siglo por la disminución de enfermas en el hospital. El salario de los curas es directamente proporcional al grado de mortandad del hospital por que cobran por misa de difuntas y entierros.

\section{Fig. 6. Madre cirujana y el botiller}

Dos oficios de un mismo rango dentro del hospital, ambos son ministros menores. La madre cirujana atiende a las enfermas con 
heridas, las prepara para cada visita del cirujano, y luego administra lo que se le indica. El botiller es el encargado de las compras al por mayor. El botiller tiene mayor capacidad adquisitiva que la madre cirujana, pero lo va perdiendo paulatinamente porque disminuyó el número de enfermas.

\section{Fig. 7. Madre mayor y patrón (San Isidoro del} Campo)

Dos oficios administrativos. El oficio cualificado administrativo va perdiendo paulatinamente su capacidad adquisitiva en forma paralela a la que la pierde la madre mayor que conduce el área femenina del hospital.

c) Los trabajos cualificados del personal sanitario masculino no descienden su capacidad adquisitiva, sino se mantienen altos, contrario a la capacidad adquisitiva del personal cualificado sanitario femenino.

\section{Explicación:}

Se procede a comparar oficios cualificados aparentemente semejantes.

\section{Fig. 8. Madre cirujana y cirujano}

El cirujano realiza sólo dos visitas de una hora cada una, en la mañana y otra en la tarde (en total dos horas) y una visita en admisión de enfermas. Mientras que la madre cirujana trabaja todo el día, e incluso duerme con las enfermas. La diferencia de salarios sigue siendo discriminatoria en el tiempo, aunque se produce una ligera convergencia o aproximación.

Conclusiones en cuanto a los trabajos no cualificados:

- No hay diferencia sustancial en el trabajo no cualificado tanto de hombres como mujeres desde mediados del siglo XVIII, tendencia que ya se visualiza desde el primer tercio del mencionado siglo.

- En los trabajos no cualificados da igual que sea hombre y mujer, de tal manera que cada vez en forma más notoria las diferencias de salarios son por criterios de renta que de género, que si se dio a finales del siglo XVI.

Conclusiones en cuanto a los trabajos cualificados

- Los trabajos cualificados de tipo administrativo descienden paulatinamente su capacidad adquisitiva acercándose a la capacidad adquisitiva de los salarios provenientes de los trabajos cualificados femeninos. Es el caso del salario del patrón San Jerónimo o secretario con el salario de la madre mayor. Sin embargo los patrones priores recibían otras entradas de dinero, además del salario: por misa de difuntas de almoneda generales, ayudas de costa del hospital de convalecencia y del hospital de la Sangre.

- Los trabajos del personal religioso descienden su capacidad adquisitiva, acercándose de forma paulatina a la capacidad adquisitiva de los salarios provenientes de los trabajos cualificados femeninos, como es el caso del cura segundo con la madre cirujana.

- Los trabajos cualificados del personal sanitario no desciende su capacidad adquisitiva, sino se mantiene alto frente a la capacidad adquisitiva del personal cualificado sanitario femenino. Por ejemplo, el cirujano y madre cirujana.

De esta manera se valora la preparación científica con mayores salarios y mayor capacidad adquisitiva y se deprecian los oficios sin cualificación, sean estas realizadas indistintamente por hombres o mujeres con menores salarios y menor capacidad adquisitiva. 
Gráficos 6: Salarios reales siglo XVIII
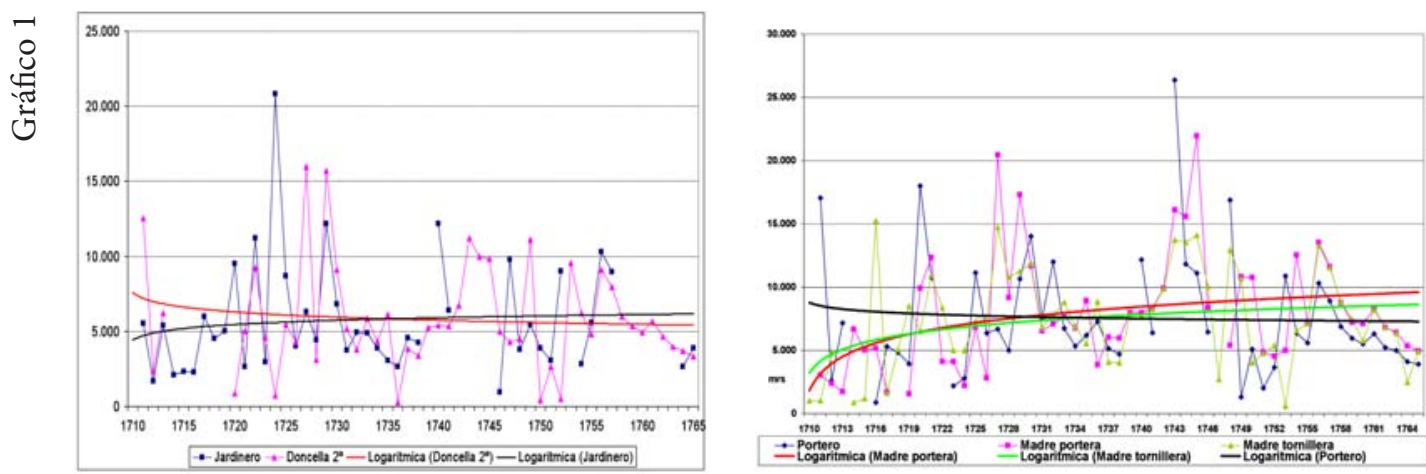

?

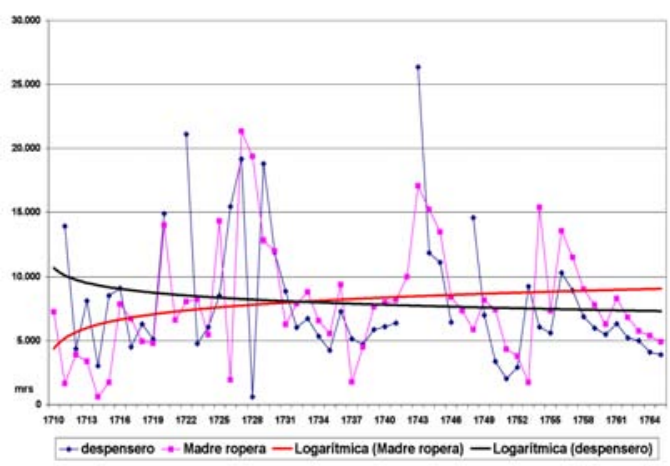

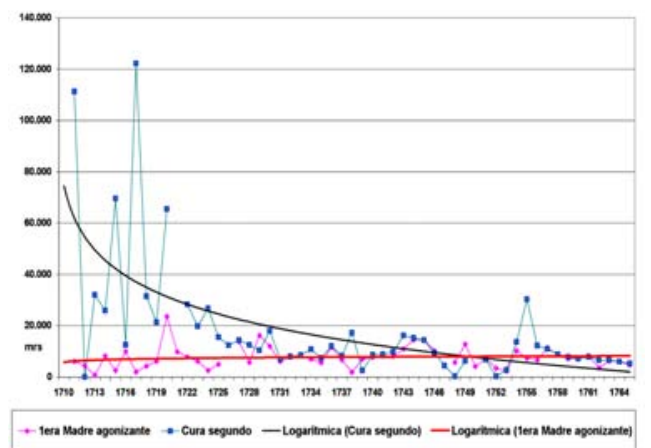

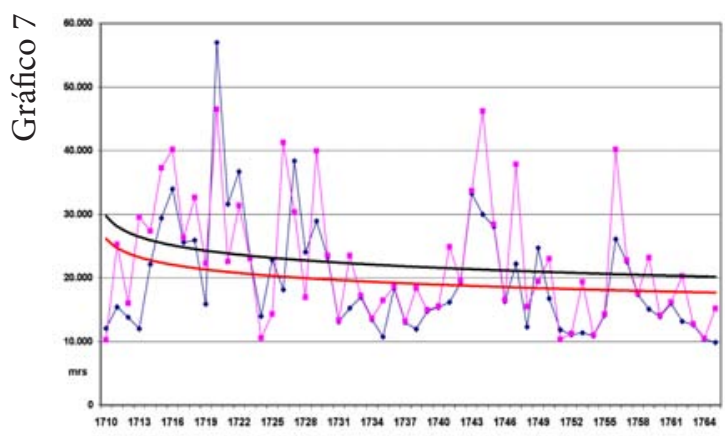

$\rightarrow$ Madre Uayor $\rightarrow$ San isidro del Campo — Logaritemica (San isidro del Campo) — Logaritmica (Madre Mayor)

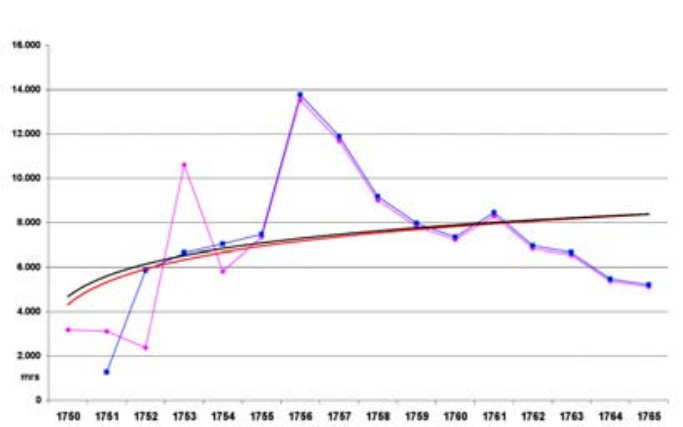

$\rightarrow$ Madre panetera $\rightarrow$ tahonero - Logaritmica (Madre panetera) - Logaritmica (tahonero)
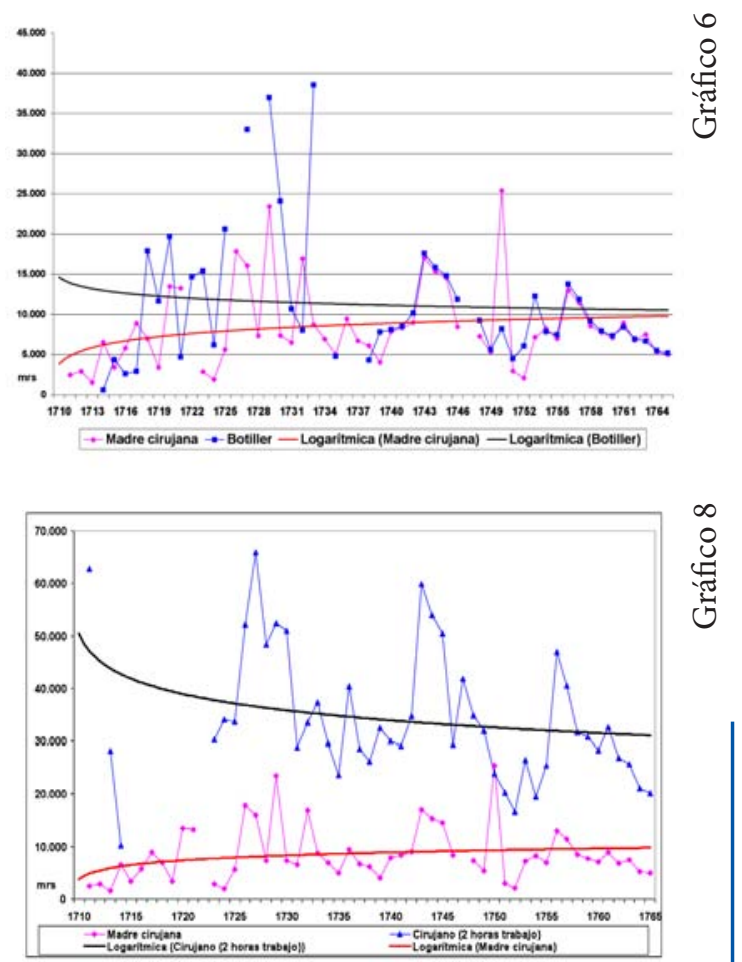


\subsubsection{Pago por especie}

El Hospital de la Sangre de Sevilla entregaba un pago por especie, además de los salarios monetarios. Este pago podía ser convertido en dinero si no se consumía la ración de alimento designada en forma diaria. Estas raciones eran importantes en una sociedad donde la carestía alimentaria era lo habitual -desabastecimiento de cereales y de carne de carnero, puerco, vaca y pescado- y los precios del trigo fluctuaban, alcanzando a veces picos altísimos y se sucedían prolongados periodos de escasez a consecuencia de ocultaciones y acaparamientos que llevaron a hambrunas en la primera mitad del siglo XVI (1503-1508, 1519-1523, 1529-1532, 1541-1542). Además, el aumento poblacional de Sevilla empeoró la situación, pues la demanda de pan creció, siendo con frecuencia la oferta muy insuficiente, por lo que Sevilla sufrió terribles hambrunas. Mientras tanto, el Hospital de la Sangre se resguardaba de este desasosiego, amparada por los ingentes bienes delegados por sus fundadores ya que contaba con tierras de labranza como el Guadalcanal que le proveía lo necesario para desarrollarse, mientras que fuera de ella reinaba el desabastecimiento, insuficiencia alimenticia, precios altos y especulación. La cocina del hospital se encargaba de preparar la comida y la panetería, los panes para los enfermos y los trabajadores, apareciendo formalmente las paneteras desde antes 1503 y la madre panetera en 1555.

Durante el primer siglo de existencia de este hospital, en ninguno de sus Reglamentos de 1503 y 1603 indica que se les daba alimentos como pago a sus servicios, lo más probable es que se haya desarrollado la costumbre entre los trabajadores de comer la misma comida de los enfermos, sin embargo a finales del siglo XVI, ya se había separado la cocina de ministros del hospital de la cocina de enfermos y criados.
El Siglo XVII significó para el Hospital de las Cinco Llagas, al menos por un tiempo, uno de los periodos de mayor esplendor económico al coincidir el desembolso de los dos grandes patronatos del tesorero de la Casa de la Moneda Diego de Yanguas y las hermanas Núñez Pérez. A consecuencia de la entrada de estos capitales fue precisamente en 1624 cuando se empezaron a entregar raciones en carne, cereales, frutas, vino, aceite, pasas a los trabajadores del hospital, atenuando la crisis galopante e imperante que se daba fuera del hospital, especialmente en los periodos de 1603-1605, 1616-1618, 1626-1628, 1677-1687,1693-1697, caracterizada por la inflación y hambre, provocada por la adversidad climática (lluviasequía). Así, se observa que el hospital era un microcosmos, protegido de las hambrunas que acechaban a extramuros de la institución por los bienes y rentas que la familia de los fundadores y de los nuevos patronatos lo habían dotado de ingentes recursos pecuniarios. Sin embargo, la crisis le impactó de manera frontal con la terrible peste de 1649 , por la que se vio obligado el hospital a despedir a parte de sus trabajadores. La recuperación total del hospital se produjo hasta varios años después de la epidemia.

El siglo XVIII fue un siglo de crisis económica que impactó al hospital, pues sus rentas ya no rendían lo suficiente, sin embargo se continuó dando las raciones diarias tanto a los enfermos como a todos los trabajadores. Otra peste que afectó seriamente al hospital fue la de 1708-9 que produjo la inflación de los cereales a tal grado que se suprimió la panadería y la atahona del hospital hasta 1755 (Carmona García, 2000). Como se observa el hospital se mostraba cada vez más vulnerable frente a los embates externos fuesen climáticos, económicos (primeras desamortizaciones), políticos, epidémicos, inflacionarios, pues sus rentas ya no tenían 
“cabimentos". Así y todo, las raciones de comida diaria no fueron suprimidas, incluso en las peores épocas se convirtió en el único pago a los ministros menores o sirvientes del hospital. Sin embargo, los peores golpees fueron la invasión francesa y la guerra de independencia que prácticamente terminaron por desestabilizar la ya precaria economía hospitalaria.
3.- Comparación esquemática entre la enfermería femenina del Hospital de la Sangre y la enfermería masculina del Hospital del Cardenal.

Se ha realizado comparaciones en cuanto al trabajo hospitalario asistencial en los dos hospitales sevillanos estudiados

\begin{tabular}{|l}
\hline Hospital de la Sangre \\
\hline El área de sanidad estaba conformado por tres \\
partes: \\
a) La medicina y cirugía: Médico y cirujano. \\
b) La enfermería: Madres enfermeras de medi- \\
cina, cirugía, incurable, convaleciente, buen \\
morir y sus doncellas. \\
c) El servicio doméstico: Madres cocineras, pa- \\
naderas, roperas, sus doncellas y una portera.
\end{tabular}

En el hospital de la Sangre se vivía en una casa de comunidad donde si bien estaban separados, alternaban en ciertos momentos del día para cumplir con sus obligaciones.

El área femenina estaba a cargo de la madre mayor que se denominaba "área de clausura". Esta área se dedicaba a la enfermería y actividades domésticas.

La madre mayor tenía ocho a nueve madres y once a quince doncellas.

En el XVII y XVIII, las enfermeras recibían el mismo salario a excepción de la madre mayor que aumentó su salario al doble de 264 reales (8.976 ms.) a 500 reales $(17.000 \mathrm{~ms}$.) desde 1730 .

\section{Hospital del Cardenal}

El área de sanidad estaba conformado por tres partes:

a) La medicina y cirugía: Médico y cirujano.

b) La enfermería: Enfermero mayor y enfermeros menores.

c) El servicio doméstico: Madre mayor, tornera y sus doncellas.

En el Hospital del Cardenal no se tenía presente esa idea y la separación fue determinante viviendo las mujeres en una torre y los varones en el hospital.

El área femenina estaba a cargo de la madre mayor que se denominaba "Cuarto de mujeres". Esta área se dedicaba sólo a actividades domésticas.

La madre mayor tenía siete u ocho doncellas y una tornera

El enfermero mayor del Cardenal recibía de salario un tercio superior a la madre mayor de su hospital y un poco menos a la madre enfermera del Hospital de las Cinco Llagas.

Enfermeros menores practicantes de cirugía del Cardenal recibían sólo un poco más que las doncellas que trabajaban como criadas en ambos hospitales. 
Una enfermera del Hospital de la Sangre (8.814 ms.) ganaba casi el doble de un enfermero menor (4.896 ms.) con excepción del enfermero "medicinero" del Hospital del Cardenal (7.344ms.).

Las enfermeras no recibían ningún tipo de enseñanza institucionalizada y formalizada, pero estaban presentes durante las inspecciones médicas y de cirugía diarias y aprendían lo que el médico les explicaba. Estaban obligadas a estar presentes durante estas visitas, para obrar en conformidad a las indicaciones del médico, bajo amenaza de despido a la que no concurriera. Había enfermeras de medicina y de cirugía

Las enfermeras no recibían una enseñanza formal en ninguna academia. Se impartía una enseñanza práctica de las madres mayores hacia las doncellas con la estricta vigilancia de la madre mayor.

La educación que impartían las mujeres era doméstica y familiar como una madre a su hija, por eso las doncellas solían denominarse "hijas".

Las enfermeras atendían a los enfermos según las prescripciones dadas por el médico o cirujano. Sangraba el barbero o cirujano

En el siglo XIX, las enfermeras y doncellas seguía cumpliendo con su función de cuidadoras.
Los enfermeros tenían una enseñanza formal en la academia de anatomía del hospital donde se enseñaba osteología, miología y angiología. Academia abierta a cualquier varón que quisiese aprender los rudimentos de anatomía.
Se obligaba la presencia de los cuatro enfermeros practicantes del hospital a la academia de anatomía bajo amenaza de despido al que no concurriera.
La enfermera mayor del Hospital de la Sangre mantuvo su salario sin aumento hasta finales del XVIII, posteriormente se redujo por la crisis generalizada que sufrió este hospital. Sin embargo, se gastaba 79.326 ms. (212 ducados) anuales en los salarios de todas las madres por ser imprescindibles para el buen desempeño del hospital.
Los enfermeros atendían a los enfermos según las prescripciones dadas por el médico o cirujano. Sabían sangrar.

En el siglo XIX, el enfermero mayor llegó a ser cirujano segundo y los enfermeros menores fueron llamados estudiantes practicantes de cirugía.

En ese mismo siglo, a las mujeres del área femenina del Cardenal, se las empezó a denominar "sirvientas", se homogenizó sus salarios y se anuló la jerarquía, desapareciendo la madre mayor.

En el siglo XVII, el salario del enfermero mayor permaneció estable, pero fue a mediados del siglo XVIII cuando se les exigió equipar su especialización a la de un cirujano. Así si bien eran denominados enfermeros mayores eran en verdad cirujanos a todo derecho y como tal se empezó a valorar monetariamente desde 1804, principalmente al enfermero mayor quien pasó a denominarse cirujano segundo. 
Hasta 1831, en el Hospital de la Sangre existió el título de madre mayor quien estaba encargada del área femenina, conformada cada vez más por sirvientas
Mientras el enfermero mayor recibía el título de cirujano segundo en 1804, desaparecía ese mismo año el cargo de madre mayor, denominando a todas las mujeres que trabajaban en el área femenina "doncellas" por no decir sirvientas. Aunque hubo una madre mayor jubilada e impedida hasta 1815 quien siguió manteniendo el titulo hasta su muerte cuando la reemplazó una mujer que ya no ostentaba ese título, aunque sí sus funciones.

El Hospital de las Cinco Llagas estaba dirigido a enfermas que no fuesen incurables ni contagiosas. Aunque hubo un área de convalecencia, otro de incurables, otro para clérigos enfermos y un área de enfermos hombres entre 1650 a 1750 . El cargo de enfermero de eclesiásticos no era constante, a veces lo cumplía el ayudante de botica.

El Hospital de la Sangre era un hospital bajo jurisdicción papal, delegada a un priorato conformada por el prior del convento de Santa María de las Cuevas de la Cartuja, y los priores de San Jerónimos de Buenavista y San Isidoro del Campo. Renunció el cabildo catedralicio de Sevilla su elección como prior.

Existía la dotación de doncellas para tomar estado de casadas que trabajaban en el hospital desde 1587.

El número de doncellas de dote fluctuó de once, doce y quince que recibían 30 o 50 ducados de vellón al casarse si cumplían una serie de requisitos.

Ganaban los salarios más bajos del hospital y durante dos siglos recibieron la misma cantidad 4.488 maravedíes (mrs), pero eran imprescindibles para el hospital, pues en sus salarios se gastaba anualmente $53.856 \mathrm{mrs}$, además de las dotes entregadas. Las doncellas de dote desaparecieron en el Hospital de la Sangre en 1809, siendo sustituidas por niñas sirvientes desde 1812 a 1833.
El Hospital del Cardenal estaba dirigido a personas heridas en forma violenta. Sin embargo sólo se admitían en camas a varones, las mujeres eran atendidas en el portal o en casos graves en cuarto aparte

El Hospital del Cardenal era un hospital bajo jurisdicción papal, delegada a un priorato conformado por el prior del convento de Santa María de las Cuevas de la Cartuja, y el prior del convento de San Jerónimo de Buenavista y por un representante del Cabildo Catedralicio de Sevilla. Sirvió de precedente y ejemplo al Hospital de la Sangre de Sevilla.

Existía dotación de doncellas que trabajaban en el hospital desde su creación en 1453.

El número de doncellas de dote fluctúo de siete a ocho con dotes de 50 ducados.

Ganaban los salarios más bajos del hospital y durante dos siglos recibieron la misma cantidad pital, pues en sus salarios se gastaba anualmente en todas ellas: $35.904 \mathrm{mrs}$, además de las dotes entregadas. Por lo que resultaban ser las más caras en cuanto a grupo.

Las madres y doncellas pierden esas denominaciones en 1814, desde cuando reciben el nombre de sirvientes. $4.488 \mathrm{mrs}$, pero eran imprescindibles para el hos- 


\begin{tabular}{|c|c|c|c|}
\hline \multicolumn{2}{|c|}{$\begin{array}{l}\text { La administración del Hospital de la Sangre era } \\
\text { similar a la del Cardenal }\end{array}$} & \multicolumn{2}{|c|}{$\begin{array}{l}\text { La administración del Hospital del Cardenal } \\
\text { era similar a la de la Sangre. }\end{array}$} \\
\hline Personal sanitario de la Sangre & Salario & Personal sanitario del Cardenal & Salario \\
\hline Médico & 74.800 & Médico & 10.000 \\
\hline Cirujano & 37.400 & cirujano & 37.400 \\
\hline Ministro boticario & 8.976 & Enfermero mayor & 10.200 \\
\hline Ayudante de boticario & 6.732 & Barbero sangrador & 10.000 \\
\hline Madre mayor & 17.000 & Boticario & 13.464 \\
\hline 10 madres enfermeras $(\mathrm{c} / \mathrm{u})$ & 8.814 & Enfermero primero Medicinero & 7.344 \\
\hline \multirow[t]{4}{*}{12 doncellas $(\mathrm{c} / \mathrm{u})$} & 4.488 & Cuatro enfermeros menores $(\mathrm{c} / \mathrm{u})$ & 4.896 \\
\hline & & Madre mayor & 8.976 \\
\hline & & Tornera & 4.488 \\
\hline & & ocho doncellas (c/u) & 4.488 \\
\hline \multirow{2}{*}{\multicolumn{4}{|c|}{$\begin{array}{l}\text { En el siglo XVII a finales del XVIII, las doncellas en ambos hospitales ganaban igual } 4.488 \text { maravedíes } \\
\text { ( } 12 \text { ducados) anuales. Las Madres mayores de ambos hospitales ganaban } 24 \text { ducados anuales más las ayudas } \\
\text { de coste, pudieron alcanzar de } 54 \text { a } 74 \text { ducados a mediados del siglo XVII. Esta cantidad se estabilizó a } 45 \\
\text { ducados para la de la Sangre y la del Cardenal fluctuó de } 24 \text { a } 41 \text { ducados en el XVIII. Además, la madre } \\
\text { tornera seguía siendo considerada de menor rango en el Cardenal, pues en la Sangre era una madre de nivel } \\
\text { intermedio, característica que se visualizaba en su salario ya que las madres intermedias de la Sangre ganaban } \\
8.814 \text { maravedíes ( } 23 \text { ducados) anuales. Sin embargo, el Hospital del Cardenal tuvo un repunte económico a } \\
\text { partir de } 1804 \text { que no tuvo el Hospital de la Sangre. Lo que llama la atención es que en el Hospital del Carde- } \\
\text { nal, las lavanderas y cocineras ganaran casi igual que los enfermeros menores. } \\
\text { El médico ganaba más en un hospital sanitario como el de la Sangre, mientras que el cirujano ganaba } \\
\text { igual en ambos hospitales a pesar del mayor rango que tenía este profesional en un hospital de emergencias } \\
\text { como el del Cardenal. }\end{array}$}} \\
\hline & & & \\
\hline \multicolumn{4}{|c|}{$\begin{array}{l}\text { Al menos durante los siglos XVI al XVIII, un estudiante de anatomía y cirugía como eran los enfermeros } \\
\text { nenores ganaban igual que las criadas que trabajaban ayudando en la limpieza y comida en el hospital del } \\
\text { ardenal. En el XIX se dio mayor valoración monetaria a los que habían conseguido una plaza de enfermero } \\
\text { través de un examen, pero se seguía pagando bajo a los estudiantes practicantes en cirugía. }\end{array}$} \\
\hline
\end{tabular}


Comparacion de los salarios de los hospitales de las Cinco Llagas y el Cardenal de Sevilla, mediados del siglo XVIII

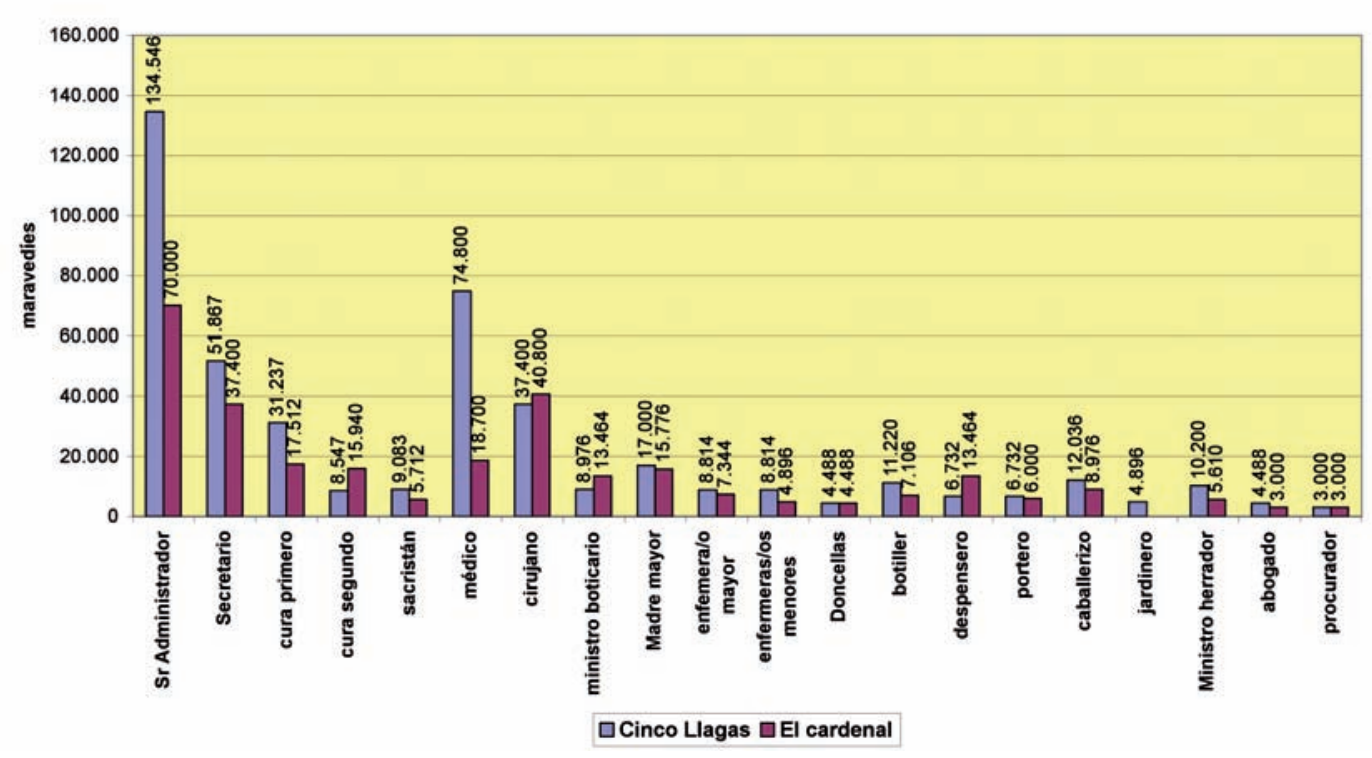

Es necesario indicar que una doncella de dote ganaba igual tanto en el Hospital del Cardenal como en la Sangre, sin experimentar cambios desde su creación. Esto fue así al menos hasta mediados del siglo XVIII, cuando se pagaba casi igual tanto el trabajo sanatorio de los enfermeros sin titulación como el trabajo doméstico de las mujeres ya que se consideraban ambos trabajos de igual importancia para el buen gobierno del hospital.

\section{Gasto anual del hospital de las Cinco Llagas por su personal sanitario, mediados del siglo XVIII (en maravedies)}

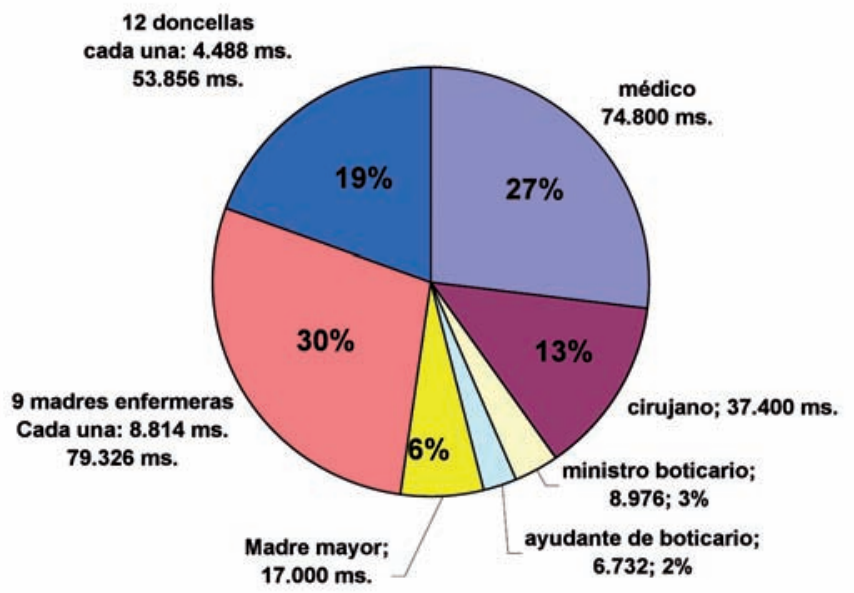

Se observa que el salario de una persona (un médico) equivalía a la de casi nueve personas (madres enfermeras), sin embargo el 55\% del presupuesto sanitario del hospital era otorgada a las veintidós mujeres que trabajaban en el hospital de la Sangre, el $45 \%$ restante le correspondía a los cuatro hombres del área sanitaria del hospital (médico, cirujano, boticario y su ayudante).

Fuente: elaboración propia 


\section{Gastos anuales del hospital del Cardenal por el personal sanitario,} mediados del siglo XVIII (en maravedies)

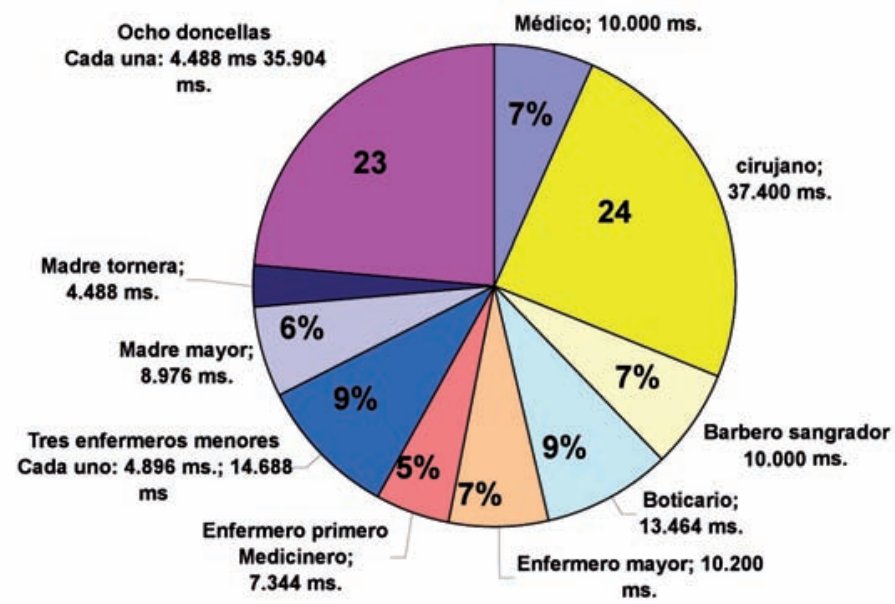

Se observa que el salario de un varón (un cirujano) equivalía a los salarios de casi la totalidad de mujeres que trabajaban en el área femenina, ocho personas (doncellas), sin embargo el 32\% del presupuesto sanitario era otorgada a las diez mujeres que trabajaban en el Hospital del Cardenal, el $68 \%$ restante le correspondía a los nueve hombres del área sanitaria del hospital (médico, cirujano, boticario, barbero, enfermero mayor, enfermero primero $y$ tres enfermeros menores).

Fuente: elaboración propia

\section{4.- El Hospital San Bartolomé de la Ciudad de los Reyes}

Un ejemplo de hospital mixto fue el Hospital San Bartolomé de la Ciudad de Lima que fue fundado en 1651 para la atención de los negros libres de la capital del Virreinato del Perú. Este hospital tenía un área masculina y otra femenina, separados y atendidos cada uno por su respectivo personal según sexo. La separación de sexos era absoluta hasta en la arquitectura: un crucero donde estaba la sala de hombres, cocinas, lavanderías, letrinas y otro crucero para la sala de mujeres con sus respectivos servicios básicos. También había una sala de aislados y contagiosos, además de una iglesia, oficinas y cuartos para uso interno de los cuidadores, botica, gallinero y huerta. (ABL.PR_0006AHBPL_HOS_SB_001(16611694), Libro de cuentas .ABL.PR_0006 AHBPL_HOS_SB_002 (18109-1821) Libro de entrada y salida de enfermos esclavos. ABL. PR_0006AHBPL_HOS_SB_004 (1795-1808) Libro de entrada y salida de enfermos hombres. ABL.PR_0006AHBPL_HOS_SB_006 (1810-1815).
Un impulso que permitió la reforma hospitalaria limeña fue la reforma universitaria de 1771 de Carlos III que se impuso en Lima durante el gobierno del virrey Manuel de Amat i Junyent. Reforma que dio importancia al estudio de la medicina. Sin embargo, la Universidad de San Marcos de Lima continuó permaneciendo escolástica, pues se resistía a las reformas, por lo que en 1808 el virrey Abascal y Sousa, a petición del protomédico Hipólito Unánue inauguró el Colegio de Medicina y Cirugía de San Fernando de Lima, dejando de enseñarse medicina en la Universidad de San Marcos, aunque ésta siguió otorgando los grados académicos (AGI, Lima 739, N 57) (Lastres, 1957). Los primeros profesionales en medicina del Colegio de Medicina y Cirugía de San Fernando fundado en 1811, necesitaron un nicho profesional donde desarrollarse como eran los hospitales, pero para incorporarlos era necesario reformar sus reglamentos para introducir a los nuevos egresados en medicina y cirugía. Una reforma fue ordenada desde la Metrópoli al virreinato del Perú a través de la Real Orden del 4 de Mayo de 1815, en 
la que se pidió a los Virreyes, Presidentes de Reales Audiencias y Gobernadores en América ordenar visitas a los colegios, seminarios, universidades, convictorios reales y hospitales. El virrey peruano que recibió esta orden fue Don José de Abascal quien decretó el 11 de octubre de 1815 esta tarea a Don Manuel Pardo Rivadeneyra para que realizara visitas en los hospitales limeños de Santa Ana, San Andrés, Espíritu Santo y San Bartolomé (Rubi Chara, 2011). En 1816, Pardo llevó a cabo una inspección ocular en el Hospital San Bartolomé de
Lima y lo encontró en malas condiciones. Un plan de reforma fue diseñada por Pardo que lo volcó en un nuevo reglamento, que se remitió a la Comisión de la Real Audiencia y que se agregó al expediente de la Visita a Hospitales en Noviembre de 1817. La constitución o Plan de Ordenanzas del Hospital San Bartolomé fue aprobada por el virrey Joaquín de Pezuela por Superior Decreto en 1817.

Según las constituciones de 1670 y 1817 , el hospital estaba conformado por el siguiente personal:

\begin{tabular}{|l|l|}
\hline \multicolumn{2}{|c|}{ Tabla 4. Hospital San Bartolomé de Lima( Personal) } \\
\hline Mayordomo & \multicolumn{1}{c|}{ Constitución de 1817 } \\
\hline Diputados & Hermano mayor \\
\hline Hermanos 24( Personas honradas libres) & Capellanes el Hospital \\
\hline Capellanes & Secretaria de la Junta \\
\hline Sacristán & De la contaduría \\
\hline & Tesorero \\
\hline & Comisario de pleitos \\
\hline & Abogados del Hospital \\
\hline & De los procuradores \\
\hline Enfermero Mayor & Del escribano del hospital \\
\hline Médico & Del Enfermero Mayor \\
\hline Cirujano & Del Médico \\
\hline Botica & Del Cirujano \\
\hline Barbero & De la Botica \\
\hline Ropero & Del Sangrador \\
\hline El portero & Del ropero \\
\hline & Del despensero \\
\hline Del Hospital de mujeres & Del Lavandero \\
\hline Enfermera & Del Hospital de Mujeres \\
& La Madre \\
& Enfermeras \\
& Sirvientas \\
& Cocinera \\
\hline Elaboración Propia: Fuente AGI (Archivo General de Indias). Lima 793 N3. \\
\hline & Del cocinero mayor \\
\hline & Otros sirvientes: bañador, colchonero \\
\hline & Personal de Dementes \\
\hline & \\
\hline &
\end{tabular}




\subsection{Comparación entre el enfermero y en-} fermera del siglo XVII y comienzos del XIX a través de las constituciones del Hospital de San Bartolomé de negros y negras libres de Lima

En el siglo XVII, los deberes del enfermero y enfermera eran asistenciales. Se encargaban de la preparación del enfermo para su debida atención por el médico y cirujano, informarles de la situación de cada enfermo, hacer cumplir la prescripción médica, avisar al capellán para que asistiese espiritualmente a los enfermos o diese la extremaunción, recorrer las salas del hospital, estar atento a las eventualidades que pudiesen ocurrir, siendo sólo suya la responsabilidad de muerte sin auxilio médico y espiritual. Las penas fluctuaban desde el descuento del salario hasta el despido. El enfermero y la enfermera tenían obligaciones similares, principalmente cumplir con las indicaciones del médico y del cirujano con los enfermos y la vigilancia de los trabajadores bajo su responsabilidad.

La constitución de 1670 indica que el área femenina estaba a cargo de la madre enfermera y sus obligaciones serían las mismas que las del enfermero en la sala de varones. Pero, la enfermera estaba supeditada al enfermero mayor al tener que informarle sus actividades. Estaba obligada a vivir dentro del gineceo del hospital y salía con licencia del mayordomo o diputados de semana, y a falta de ambos, del capellán de la semana. Sus deberes incluían la asistencia diaria en las salas, tocar la campana para anunciar y prevenir a las enfermas la entrada del médico y cirujano y avisar a todos los demás que tenían la obligación de asistir a la visita del médico para enterarse de los avances o retrocesos de cada enfermo.

La enfermera mayor cumplía con administrar las recetas médicas, avisar al capellán de turno a cualquier tiempo u hora sobre los enfermos que necesitaban consuelo espiritual o los sacramentos, velar y asistir en todo momento a todas las enfermas de las salas del hospital a su cargo, pues "suelen haber accidentes en los achaques y si en esta parte hubiere alguna omisión, o falta, siempre recaerá sobre dicha enfermera" y ocuparse sólo de la atención a la enferma. El ropero estuvo a cargo de la limpieza de la sala y de la muda de ropa limpia de las camas (AGI. Lima 793 N3).

En este periodo, el enfermo mayor se ocupaba del área masculina y la enfermera mayor se ocupaba del área femenina y tenía mayor libertad de acción y decisión ya que disponía de la alimentación según la receta médica y a falta de ésta podía determinar el tipo de comida a suministrar al enfermo, según su experiencia (libertad de decidir): "Antes de repartir la comida y cena que ha de ser por sus manos ira reconociendo los enfermos, y a cada uno en particular para que conforme la receta o achaque se le da la comida”. La enfermera recibía un salario sobre el que se la penalizaba si no cumplía con sus obligaciones: "y si acaso hiciere alguna ausencia, o faltare en alguna de las obligaciones de su cargo por cada una, se le descontaran dos pesos del salario" (AGI. Lima 793 N3).

Las cuidadoras y enfermas vivían recluidas en el gineceo del hospital, controladas por el portero que era el encargado de "no dejar entrar mujeres para las salas de hombres" $y$ viceversa, ni comidas ni otra cosa para las enfermas. Se permitía sólo con licencia del mayordomo, diputado y capellán. La madre enfermera era responsable de todas las faltas, omisiones y descuidos, que se experimentaban en las salas, a menos que no lo pudiese evitar en tal caso debía dar parte "a los superiores" para la respectiva enmienda, y reprensión o 
castigo de las que contraviniesen a las órdenes que se habían comunicado. De esta manera, no tenía potestad de castigar, sino sólo informar a sus superiores.

Cambios en el área femenina se habrían dado en el siglo XIX, tal como indica la constitución de 1817. La madre enfermera continuaba a cargo de las enfermeras menores, cocineras y lavanderas, en cuanto a cuidado y alimentación de los pacientes y vigilancia del personal, pero sólo cumplía órdenes y no tomaba decisiones, y si ocurría alguna novedad se le avisaba al enfermero mayor para que decidiera. Sólo cumplía con las disposiciones. Por ejemplo: la ropa y utensilios del hospital de mujeres lo determinaba el enfermero mayor; el inventario lo hacía el ropero y la enfermera mayor sólo recibía y se hacía responsable de su cuidado. No tenía ninguna potestad de determinar los alimentos para los pacientes, pues en caso de un imprevisto debía avisar al enfermero mayor.

No estaba obligada a saber leer y menos escribir. También continuaba acompañando al médico y al cirujano durante las visitas para informarles el estado de cada enferma y recibir las indicaciones del suministro de medicinas y de los alimentos. El enfermero menor que era un practicante de medicina la asistía para que se aplicara lo señalado por los facultativos, a menos de ocurrir particular novedad, en cuyo caso avisaba al enfermero mayor, para que dispusiese lo que conviniese.

Sin embargo, la enfermera mayor continuaba enseñando con el ejemplo y vigilaba el trabajo y comportamiento de las otras enfermeras y sirvientas. Una de las principales obligaciones de la madre enfermera era vigilar que las enfermeras menores cumpliesen con sus deberes de barrer las salas a las horas establecidas, curar, limpiar y hacer las camas, que las lavanderas lavaran toda la ropa y que las cocineras elaborasen las comidas diarias y limpiaran la cocina y el menaje. La madre enfermera continuaba vigilando que durante las visitas a las enfermas no entrase: "Ningún hombre sin licencia del hermano mayor, que no sea el padre, hijo, o marido, y ninguna mujer que no tenga inmediata conexión; y menos el que lleven comida, o bebida, o algún medicamento; ni tampoco dejar salir a las enfermas de sus salas, antes de que por el médico o cirujano se les de licencia para ello" (AGI, Lima 793 N3).

En contraste, el enfermero mayor sí tuvo una innegable evolución en su profesión que rebasó a la enfermera, al superar su situación de cuidador - religioso y se convirtió en egresado de estudios en medicina y cirugía del Colegio San Fernando. La enfermería masculina se dividió en enfermeros médicos y enfermeros cirujanos. Así, ya no era sólo un enfermero, sino también un médico-cirujano residente en el hospital. Su labor se complementó y enriqueció combinando ciencia con técnica. Esto se hizo con el claro propósito de poder superar las emergencias que pudieran suceder en el hospital durante la noche o en horas inconvenientes.

Las actividades del enfermero mayor eran amplias:

- Como enfermero: Cuidado y atención al enfermo, preparar la historia de los pacientes para la llegada del médico y cirujano, controlar la limpieza del recinto, avisar al capellán para la realización de la extremaunción a los moribundos, realizar el seguimiento de sus enfermedades.

- Como médico o cirujano: recetar medicinas y alimentos. También operar

- Como docente: gran parte de sus tareas estaba orientada a su labor docente con los 
practicantes en medicina o cirugía del Colegio de Medicina y Cirugía de San Fernando. Estos estudiantes estaban vigilados por el enfermero mayor y el hermano mayor. Se les controlaba no sólo los avances en los estudios, sino también su aptitud y conducta. Se exigía respeto a la institución.

- Como administrador: control de los practicantes, sirvientes y de otras personas en el hospital

\subsection{Comparación esquemática entre la enfer-} mería femenina de los hospitales de las Cinco Llagas de Sevilla y el Hospital de San Bartolomé de negros y negras libres de Lima en los siglos XVII, XVIII y comienzos del XIX

Las constituciones de ambos hospitales tenían incluidas las obligaciones de la enfermera femenina. En la constitución de $1624 \mathrm{del}$ Hospital de las Cinco Llagas de Sevilla y en la Constitución de 1661 del Hospital de San Bartolomé, a las mujeres que ejercieran el oficio de enfermeras, no se les exigía requisitos de tipo profesionales-académicos, sólo características personales, de tipo ético-religiosas y morales, pues únicamente se pedía a las aspirantes a enfermeras que fuesen personas capaces de tratar a las enfermas con mucho cuidado y mucha caridad.

Las Constituciones de 1624 y 1734 del Hospital de las Cinco Llagas de Sevilla y de 1817 del Hospital de San Bartolomé de Lima, además de responsabilidades asistenciales, a la enfermera mayor también le asignaba una compromiso docente, de enseñar a través del buen ejemplo al personal hospitalario femenino: doncellas y criadas. En el caso del Hospital de la Sangre de Sevilla, la docencia la ejercieron todas las madres enfermeras, incluso la madre mayor en sus respectivas áreas y ámbitos de trabajo
En cuanto a las diferencias, la enfermería fémina en el hospital de la Sangre estaba más desarrollada y especializada que el hospital de San Bartolomé de Lima. La dirección estaba a cargo de la Madre mayor la cual tenía una ayudanta. Las diferentes dependencias del hospital estaban a cargo de distintas enfermeras: Madre cirujana, Madre portera, Madre panetera, Madre tornillera, Madre agonizante, Madre cocinera, Madre ropera y 12 doncellas aprendices de enfermería. En el hospital de San Bartolomé de Lima, la enfermería femenina estaba centrada en la enfermera mayor que tenía a su cargo criadas, sirvientas, cocineras y lavanderas.

En ambos hospitales las mujeres que trabajaban recibían mensualmente un salario y ración diaria de alimentos propios de la región, en el hospital sevillano recibían carnero, vaca, gallinas, mientras que en el hospital limeño, pollo, arroz, mazamorra (dulce típico).

En el hospital de la Sangre, las madres enfermeras y doncellas podían ser reemplazadas temporalmente en caso de enfermedad. En este hospital, el conocimiento acumulado por la madre jubilada era valorado y como tal cumplía funciones docentes a las nuevas generaciones, incluso podía llegar a tener una jubilación pagada y seguir viviendo en el hospital. Por lo contrario, en el hospital limeño no existió ni el reemplazo por enfermedad, ni la jubilación pagada. Sin embargo, según las constituciones, en el siglo XVII, la enfermería femenina en el Hospital de San Bartolomé tuvo más libertad de acción, pues no estuvo tan coaccionado en sus funciones como comienzos del XIX, a raíz de las reformas que se implantaron allí.

En el hospital de la Sangre aumentó el número de mujeres que trabajaban en el área femenina y existieron patronatos que dotaban a doncellas que allí trabajaban. Esto último 
no existió en el hospital limeño estudiado. Asimismo, en el hospital de la Sangre se propuso la creación de una academia en 1750. La no concreción de estas ideas hizo que se mantuviera el sistema de madres y doncellas que atendían a las enfermas por más tiempo, aunque a veces se hacían disecciones cadavéricas para averiguar la causa de un deceso. El hospital permitió en ingreso de estudiantes de medicina internos al área femenina cuanto se convirtió en Hospital General al producirse la centralización de los hospitales sevillanos en 1837. De igual manera, el hospital San Bartolomé en Lima habría sido utilizado como lugar de prácticas de los estudiantes de medicina del Colegio de Medicina y Cirugía de San Fernando desde comienzos del XIX, a raíz de las reformas propiciadas en los hospitales. Esto provocó que se sustituyera al enfermero mayor por un médico interno quien enseñaba a los estudiantes las clases prácticas de anatomía. Marcando amplias diferencias con la enfermera mayor quien continuó siendo sólo una asistente del cuidado a los enfermos

\section{CONCLUSIONES}

Los acontecimientos políticos, culturales, económicos y sociales producidos en la transición de la modernidad a la contemporaneidad a fines del siglo XVIII a comienzos del XIX, desencadenaron cambios sustanciales en el cotidiano devenir de la vida hospitalaria. Así, el desarrollo y estudio de la medicina y el paulatino número de egresados de las instituciones donde se formaban, entre otras causas, transformó el cuidado en los hospitales que produjo, incluso, la suplantación del ancestral trabajo asistencial femenino ejercido en los hospitales de mujeres por practicantes en medicina. Estos cambios se dieron de manera casi simultánea en la Metrópoli como en las Indias.
Así, por ejemplo, la reforma hospitalaria en el hospital de San Bartolomé de la ciudad de Lima se ajustaba a las nuevas necesidades y perspectivas en cuanto al trabajo hospitalario que provocaría que el enfermero mayor tuviese una innegable evolución en su profesión que rebasaría a la enfermera. Así, el enfermero superaría su situación de cuidador - religioso y se convertiría en egresado de estudios en medicina y cirugía del Colegio San Fernando de la Universidad San Marcos. En el siglo XIX, en el hospital de San Bartolomé de Lima, la enfermera se mantuvo en su labor asistencial - técnica, cumplimiento de las prescripciones médicas y la docencia impartida a enfermeras menores a través del ejemplo. Con la reforma propuesta en 1817, a la enfermera mayor se le fue quitando cada vez más responsabilidades que se adosaban a otros. Una manera de limitarlas fue que no se les exigía ni la más mínima preparación intelectual, ni siquiera saber leer ni escribir. Teniendo necesariamente que depender de otros a tal grado que las recetas eran escritas y leídas por el practicante en turno.

La reforma propuesta en el hospital quitaba a la enfermera mayor, la responsable del área femenina, toda capacidad de decisión sobre su área, ocupándose sólo a cumplir con lo indicado para el cuidado de los enfermos. No podía ni sancionar a sus subalternos, la decisión la tenía el enfermero mayor. De esta manera, la enfermera estaba cada vez más supeditada al enfermero mayor, médico, cirujano y hasta al practicante en medicina y sus actividades se restringían cada vez más a la vigilancia de las enfermeras menores y sirvientes.

Los cambios políticos sociales y económicos alteraron a los dos hospitales sevillanos estudiados de diferente manera. Se trataba de dos hospitales hermanos regidos por casi los mismos priores, pero con diferente tratamien- 
to por ser uno hospital de mujeres y el otro de varones. En el Hospital de mujeres de las Cinco Llagas se mantuvo la transmisión del conocimiento de forma empírica de madres a hijas, tal cual una familia, amparadas por un centro religioso que actuaba como casa de comunidad y reclusión de mujeres, mientras que el Hospital del Cardenal, especializada en cirugía trasmitía los conocimientos de forma científica por los médicos y los cirujanos a los enfermeros a través de una academia de anatomía.

\section{BIBLIOGRAFÍA}

- Barriga Guillen, C., Heredia Herrera, A. et al. (1997). Hospitales y centros benéficos sevillanos: inventarios de sus fondos. Archivo de la Diputación Provincial de Sevilla.Sevilla: Diputación Provincial de Sevilla.

- Borderías Mondejar, C. (2006). El trabajo de las mujeres: discursos y prácticas. En I. Morant, (dir.), Historia de las mujeres en España y América Latina del siglo XIX a los umbrales del XX 353-380. Madrid: Cátedra Historia.

- Borderías Mondejar, C. y Carrasco, C. (1994). Las mujeres y el trabajo: aproximaciones históricas, sociológicas y económicas. En: Las mujeres y el trabajo. Rupturas conceptuales. Icaria, 15-65.

- Bravo Lozano, J. (1996). Fuentes para el estudio del trabajo femenino en la edad moderna: el caso de Madrid a fines del S. XVII. En M. Matilla y M. Ortega (eds.), El trabajo de las mujeres: siglos XVI- XX VI jornadas de investigación interdisciplinaria sobre la mujer 143-160. Madrid: Universidad Autónoma de Madrid.

- Cabré I Pairet, M. (1999). Mujeres y salud: prácticas y saberes. Dynamis, 19,17-400.

- Cabre I Pairet, M. (2006). Como una madre, como una hija: las mujeres y los cuidados de salud en al Baja Edad Media. En I. Morant, I (dir.), Historia de las mujeres en España y América Latina de la prehistoria a la edad Media Vol.I 637-657. Madrid: Ediciones Cátedra.

- Cabré I Pairet, M. (2008). Women or healers? Household practices and the categories of health care in late medieval Iberia. Bulletin of the History of Medicine, 82, (1),18-51.
- Carbonell Esteller, M. (1989). Hecho y representación sobre la desvalorización del trabajo de las mujeres (siglos XVI-XVIII). En C. Sánchez y V. Maquieira d’Angelo (eds), Mujeres y Hombres en la formación del pensamiento occidental: Actas de la VII Jornadas de Investigación Interdisciplinaria Vol.II, 157-171. Universidad Madrid: Autónoma de Madrid. Instituto Universitario de Estudios de la Mujer.

- Carmona García, J. I. (2009). Las redes asistenciales en la Sevilla del Renacimiento. Sevilla: Universidad de Sevilla.

- Domínguez-Rodiño y Domínguez-Adame, E. (1989). El Hospital de las Cinco Llagas, en Hospitales de Sevilla. Utrera: Real Academia Sevillana de Buenas Letras. Grafitres S. L.

- García Martín-Caro, C. y Martínez Martín, M. L. (2001). Historia de la enfermería: Evolución histórica del cuidado enfermero. Madrid: Harcourt.

- Gil Ambrona, A. (1996). Entre la oración y el trabajo: las ocupaciones de las otras esposas, siglos XVI- XVII. En M. Matilla y Ortega, M. (eds.), El trabajo de las mujeres: siglos XVI- XX. VI jornadas de investigación interdisciplinaria sobre la mujer 91-105. Madrid: Universidad Autónoma de Madrid.

- Gimémez Muñoz, M. del C. (2006). Breve historia de los establecimientos benéficos en Sevilla. Hispania Nova: Revista de Historia Contemporánea,6. Disponible en: http://hispanianova.rediris.es/6/articulos/6a005.pdf

- González Díaz, A. M. (1997). Poder urbano y asistencia social. El Hospital de San Hermenegildo de Sevilla (1543-1837). Sevilla: Diputación de Sevilla.

- Herrera Dávila, J. (2010). El hospital del Cardenal de Sevilla y el Dr. Hidalgo de Agüero. Visión Histórica Sanitaria del Hospital de San Hermenegildo (1455-1837). Sevilla: Ediciones de la Fundación de la Cultura Andaluza.

- Morgardo, A. (1587). Historia de Sevilla en la cual se contienen sus antigüedades, grandezas y cosas memorables en ella contenidas desde su fundación hasta nuestros tiempos. Sevilla: Imprenta de Andrea Pescioni y Juan de León.

- Ortiz de Zúñiga, D. (1766). Anales Eclesiásticos y seculares de la muy noble y muy leal ciudad de Sevilla. Madrid: Imprenta Real (Tomos IV y V). 


\section{ᄃultura de las Cuidados}

- Peraza, L. de (1997). Historia de la imperial ciudad de Sevilla (1535). Colección Clásicos sevillanos. Sevilla: Ayuntamiento de Sevilla.

- Perry, M. E. (1993). Ni espada rota ni mujer que trota: mujer y desorden social en la Sevilla del Siglo de Oro. Barcelona: Crítica.

- Ponsot, P. (1989). Atlas de historia económica de la baja Andalucía: siglos XVI-XIX. Madrid: Editoriales andaluzas.

- Ramos Castillo, A. (2003). La sanidad Sevillana en el siglo XIX: El Hospital de las Cinco Llagas. Sevilla: Diputación de Sevilla.

- Rey Castelao, O. (2010). Trabajando en cubierto. Las empleadas institucionales a fines del Antiguo Régimen. Melanges de la Casa de Velásquez. El trabajo de las mujeres en España (desde la Antigüedad al siglo XX), 40(2), 73-93.

- Rivasplata Varilllas, P. E. (2011). Las doncellas de dote del Hospital de las Cinco Llagas de Sevilla: una lectura en clave de género. Berlín: Editorial Académica Española.

- Rivasplata Varilllas, P. E. (2012). Aproximación histórica de la enfermería femenina en Europa y América. La enfermería en el hospital de las Cinco Llagas de Sevilla y los hospitales de Lima en el XVIII y parte del XIX. Berlín: Editorial Académica Española.

- Rivasplata Varilllas, P. E. (2014). La clausura femenina del hospital de las Cinco Llagas de Sevilla en el Antiguo Régimen. Cultura de los Cuidados, XVIII, 39, 48-62.

- Rivasplata Varilllas, P. E. (2015). Los hospitales de Lima colonial y su lenta y tardía reforma. Nueva Crónica 5, Enero, 131-150.

- Rubi Chara, M. (2011). El Hospital de San Bartolomé de Lima (1646-2000). La protección de la gente de color. En: Historia de la Medicina del Perú. Tomo III. Grahuer, Lima.

- Valcárcel, C. D. (1955). Reforma de San Marcos en la época de Amat. Lima: Editorial Universidad Nacional Mayor de San Marcos.

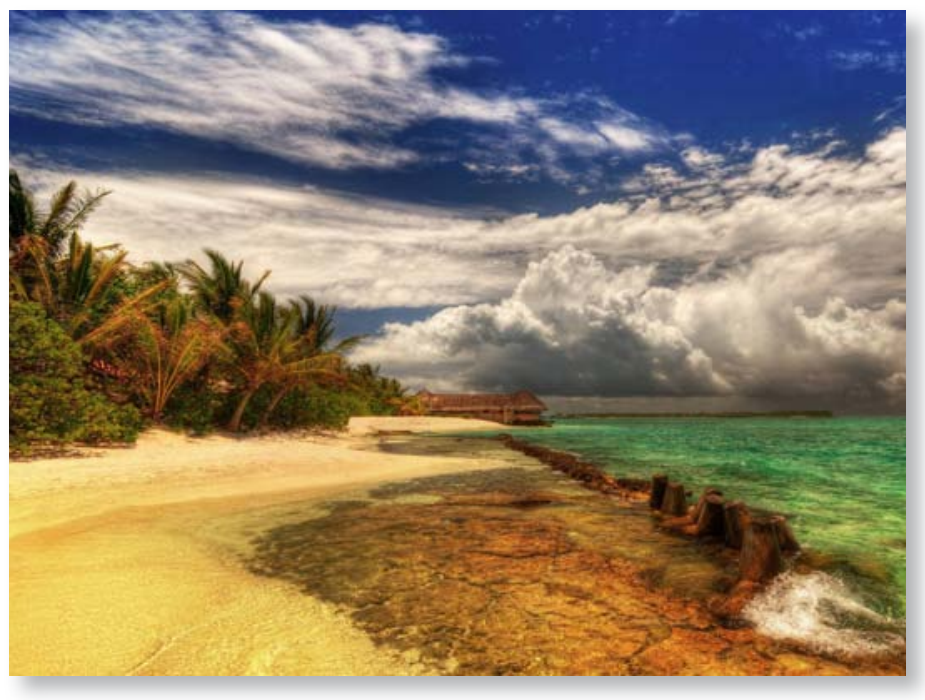

